\title{
Burial and decomposition of plant pigments in surface sediments of the Baltic Sea: role of oxygen and benthic fauna
}

\author{
Alf B. Josefson ${ }^{1}$, Joanna Norkko ${ }^{2,3,4}$, Alf Norkko ${ }^{2,4,5}$ \\ ${ }^{1}$ Department of Bioscience, Aarhus University, 4000 Roskilde, Denmark \\ ${ }^{2}$ Marine Research Centre, Finnish Environment Institute, PO Box 140, 00251 Helsinki, Finland \\ ${ }^{3}$ Environmental and Marine Biology, Department of Biosciences, Åbo Akademi University, Artillerigatan 6, 20520 Åbo, \\ Finland \\ ${ }^{4}$ Tvärminne Zoological Station, University of Helsinki, 10900 Hanko, Finland \\ ${ }^{5}$ Department of Marine Ecology-Kristineberg, University of Gothenburg, 45034 Fiskebäckskil, Sweden
}

\begin{abstract}
Degradation and burial of organic matter in sediments are important processes for oxygen dynamics and thus for the outcome of eutrophication. To assess the influences of bottomwater oxygen and macroinvertebrate fauna function on these processes, we investigated distributions of phytopigments as markers of phytoplankton detritus in surface sediments across the Baltic Sea. We compared pigment concentrations among sites with different oxygen levels and different values of a bioturbation potential index combining abundance, individual size and species-specific rankings of mobility and sediment reworking (BPI). BPI was positively influenced by oxygen availability, with a threshold at 45 to $90 \mu \mathrm{mol} \mathrm{l}^{-1}$, below which it decreased rapidly to zero in anoxic sediments. There was significant co-variation between pigments and both oxygen and BPI after accounting for differences in pigment concentrations with sediment depth and among different sub-areas, which were largely attributed to different inputs of phytoplankton. Negative correlations between pigments and both BPI and oxygen in communities dominated by Macoma balthica and Scoloplos armiger, and between pigments and BPI in the upper sediment layers inhabited by Monoporeia affinis and Pontoporeia femorata, suggested increased degradation with increasing bioturbation. Positive correlations between pigments and BPI in communities dominated by Marenzelleria spp. suggested mainly burial, which also was supported by positive correlations between Marenzelleria abundance and both sediment water content and the freshness of buried organic material. It is hypothesised that a shift from sensitive resident species like Monoporeia or Scoloplos to the more hypoxia-tolerant Marenzelleria will slow down overall degradation rates, counteracting hypoxia formation in the bottom water.
\end{abstract}

KEY WORDS: Baltic Sea $\cdot$ Bioturbation $\cdot$ Plant pigments $\cdot$ Oxygen $\cdot$ Burial

\section{INTRODUCTION}

Degradation and burial of organic matter in the sediments are processes of major importance for oxygen uptake in near bottom waters in the Baltic Sea and elsewhere. Whilst degradation will act to in- crease oxygen demand, burial will, under some circumstances, act to decrease degradation rates and the oxygen demand. To mitigate hypoxia it is therefore important to quantify factors that influence these processes. There is an increasing body of experimental work suggesting that degradation of organic mat- 
ter, including pigments, in anoxic environments is slower than in oxygenated environments (e.g. Sun et al. 1993, Bianchi et al. 2000, Sun \& Dai 2005) and that some macrofauna may enhance degradation rates of phytoplankton material (e.g. Bianchi et al. 2000, Ingalls et al. 2000, Sun \& Dai 2005). Sometimes the effect of macrofauna activities may increase burial of phytodetritus (e.g. Josefson et al. 2002, Quintana et al. 2007). There are, however, relatively few field studies to verify or disprove the experimental findings (but see Levin et al. 1997, Woulds et al. 2007, Woulds \& Cowie 2009).

Previous field work across oxygen minimum zones (OMZ) has greatly increased our knowledge of how oxygen influences benthic communities and organic matter cycling at the sea floor (Levin 2003, Woulds et al. 2007, 2009). The present area of study, the brackish Baltic Sea is, like OMZ-influenced areas, characterized by strong oxygen gradients having several anoxic basins devoid of macroscopic life. Also, the oxygenated areas are, due to low salinity, populated by relatively few macrofauna species and are, consequently, functionally simple communities. This makes the brackish Baltic Sea an ideal area for field verification of experimental results on the role of fauna and oxygen availability for the fate of phytodetritus, because in a given locality there is less confounding interference between different types of functions compared to fully marine areas rich in species.

Plant pigments like chlorophyll a (chl a) and carotenoids have often been used as biomarkers of phytoplankton in marine sediments (e.g. AbeleOeschger 1991, Bianchi et al. 1996, Morata \& Renaud 2008), where they may tell us something about both origin, i.e. phyto-group identity (Jeffrey \& Vesk 1997) and amount of carbon flux to the bottom (Bianchi et al. 2002), as well as bioturbation by animals (e.g. Boon \& Duineveld 1998, Josefson et al. 2002), including feeding of different organism groups. For example, the formation of the chl a breakdown products phaeophorbides may result mainly from metazoan grazing (e.g. Bianchi et al. 1988, 2000). In the present study we used plant pigments as markers of phytoplankton organic matter in the sediments from 23 sites scattered over a major part of the Baltic Sea and related levels and depth distributions of pigments to large-scale primary productivity and sedimentation data as well as to oxygen conditions in the bottom water and to bioturbation activities of the macrofauna. As a measure of bioturbation impact we used a modification of the bioturbation potential index (BPI) (cf. Solan et al. 2004), which includes abundance and individual size (biomass) for each species, as well as a species-specific classification of mobility and sediment reworking mode.

The level of primary production (PP), as well as the relative contributions of different phytoplankton groups, varies considerably among different regions of the Baltic Sea (e.g. Hagström et al. 2001, Wasmund \& Siegel 2008, Klais et al. 2011). The same is true for sedimentation rates (Mattila et al. 2006). For instance, PP and peak spring bloom biomass are low in the Bothnian Bay and high in the Gulf of Finland and the Baltic Proper (Wasmund et al. 2001, Sandberg 2007, Leipe et al. 2011). Cyanobacteria blooms are frequent in summer in the Gulf of Finland and parts of the Baltic Proper (Finni et al. 2001) but almost never occur in the Bothnian Bay and seldom occur in the Bothnian Sea (HELCOM 2009). However, in addition to probable regional differences in inputs of phytoplankton to the bottoms, there are gradients nested within regions of oxygen and of fauna abundance/BPI where presence of fauna is dependent on availability of oxygen. We tested for differences in pigment concentrations among regions and among different depth strata in the sediments using oxygen or BPI as covariates. We applied this approach in 3 different sub-areas, each with oxygen gradients reaching from normoxia to hypoxia/anoxia (the Gulf of Finland, Eastern Gotland basin and Southern Baltic). We also sampled in the Bothnian Sea and the Bothnian Bay, where there are no problems with hypoxia.

We addressed the following working hypotheses:

(1) Levels and composition of pigments differ between sub-areas. We expected higher pigment levels in sub-areas with higher primary production, and more cyanobacteria and higher total pigment levels in the Baltic Proper and the Gulf of Finland than in the Bothnian Sea or Bothnian Bay.

(2) Within sub-areas pigment levels are influenced by oxygen availability and macrofauna bioturbation. Specifically, we expected that pigment concentrations would be higher in areas with low or no oxygen than in areas with higher oxygen concentrations and abundant macrofauna. This negative relation between oxygen and both BPI and pigment concentrations was expected because of generally slower pigment degradation rates in anoxic areas, and because bioturbation generally increases oxygen availability deeper in the sediment.

(3) The fauna affects pigment composition. We expected a high phaeophorbide:phaeophytin ratio in the dwelling zone of macrofauna because previous work indicates phaeophorbide formation mainly through metazoan grazing. 


\section{MATERIALS AND METHODS}

\section{Sampling scheme and study area}

In May and June 2009, a survey was conducted in the Baltic Sea with sampling at a total of 23 sites (Fig. 1). To better investigate the interactions between oxygen concentrations, pigments and macrofauna, 17 of these sites were chosen to encompass gradients of increasing hypoxia in 3 areas that have different salinity-driven background diversity during normoxia: the Gulf of Finland, Eastern Gotland Basin, and Southern Baltic (diversity increasing from north to south; Villnäs \& Norkko 2011). The remaining sites were in the normoxic Bothnian Sea and Bothnian Bay.

Pigments and faunal abundance were analysed from 2 GEMAX cores $(9 \mathrm{~cm}$ inner diameter) taken at each station, except for Stn GOF6, where only 1 core was taken. Each core was photographed to obtain a visual estimate of the biogenic mixing depth and was

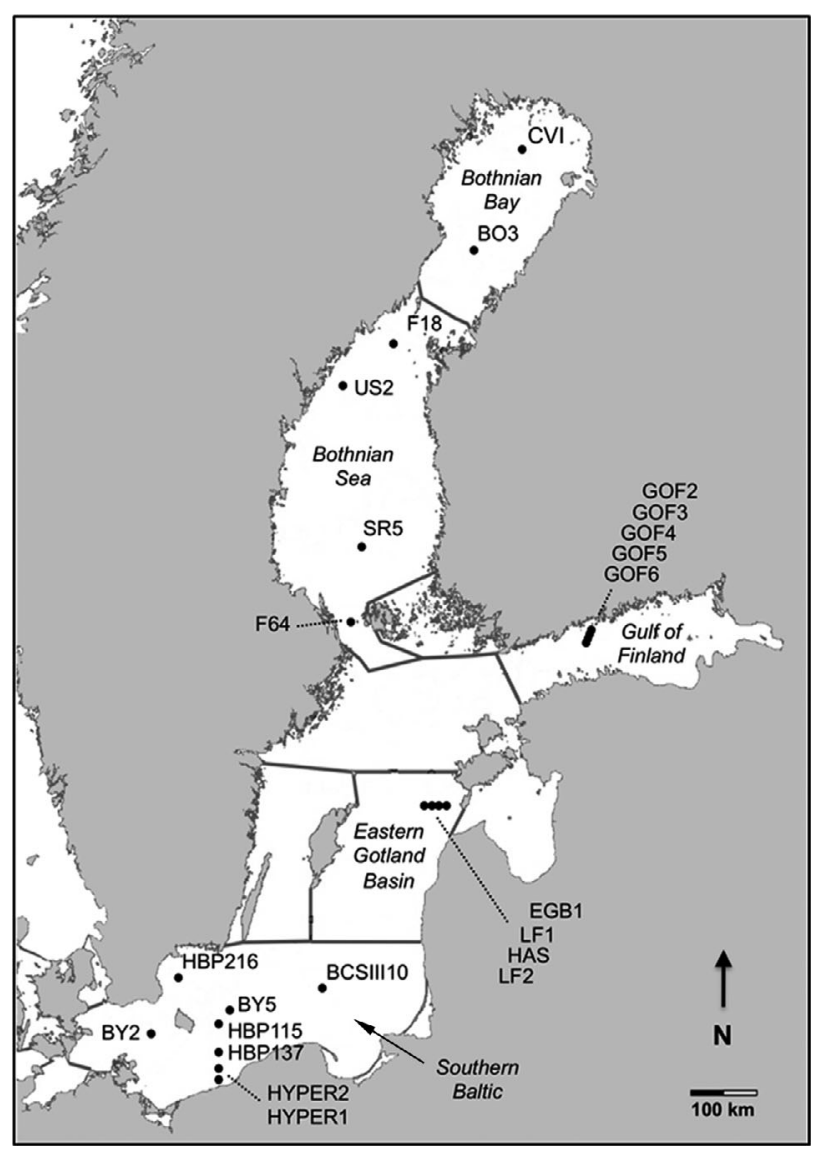

Fig. 1. Baltic Sea area with the 5 sub-areas indicated in italics and arbitrarily delimited by lines and land contours (Bothnian Bay, Bothnian Sea, Gulf of Finland, Eastern Gotland Basin and Southern Baltic, where the 2 latter areas are situated in the Baltic Proper), and sampling sites identified as in Table 2 then vertically sectioned into 7 slices: $0-1 ; 1-2 ; 2-3$; $3-5 ; 5-8 ; 8-12$; and $12-16 \mathrm{~cm}$ within $1 \mathrm{~h}$ after sampling. Slices were homogenised before subsampling (approx. $2 \mathrm{ml}$ sample) for pigments, and subsequently the remains ( $>90 \%$ of the original slice) were sieved to extract benthic macrofauna. Pigment samples were kept frozen in the dark $\left(-20^{\circ} \mathrm{C}\right)$ until freeze-dried. Due to damage to the laboratory during transport, data were lost from the following stations, all in the Bothnian Sea and Bothnian Bay - F18: one 0-1 and one $3-5 \mathrm{~cm}$ section in 2 different cores; US2: one 12-16 cm section; F64: sections 5-8, 8-12 and 12$16 \mathrm{~cm}$ in one core; BO3: $0-1,2-3$ and $3-5 \mathrm{~cm}$ in one core and $3-5 \mathrm{~cm}$ section in the other core; CV1: section 5-8 in one and 2-3 in the other core. The total number of samples/sections analysed was 303. Bottom water oxygen content was measured using Winkler titration. While all samples from all strata were used to calculate inventories, a somewhat smaller subset was used to test for effects of fauna and oxygen. The subset was: (1) mean concentration in the top $\mathrm{cm}$ $(0-1 \mathrm{~cm})$, i.e. a stratum highly influenced by recent inputs and fauna feeding; (2) the stratum from 1 to $3 \mathrm{~cm}$ depth representing the main dwelling zone of the fauna (1-2 and 2-3 cm sections); and (3) a deeper stratum composed of sections $5-8$ and $8-12 \mathrm{~cm}$.

In order to compare species and/or communities and their likely contribution to ecosystem function in terms of bioturbation, we used, in addition to the number of individuals per core, the bioturbation potential index (BPI) modified after Solan et al. (2004):

$$
\mathrm{BPI}=\Sigma A_{i} \times B_{i}^{0.5} \times M_{i} \times R_{i}
$$

where the summation $(\Sigma)$ is over all species at a site. $A_{i}$ is the number of individuals per $\mathrm{m}^{2}, B_{i}$ is the average individual biomass, (in $\mathrm{g}$ wet weight, square root transformed to linearize the effect of biomass), $M_{i}$ is the mobility, and $R_{i}$ is the reworking mode of the species $i$ at a site ( $M_{i}$ and $R_{i}$ both scored on a categorical 1 to 5 scale based on biological trait information). Mobility was scored as: $1=$ grazers on the sediment surface $; 2=$ grazers in a fixed tube; $3=$ limited movement; 4 = slow movement through the sediment; and 5 = free movement via burrow system. Reworking was scored as: 1 = epifauna bioturbating at the sediment-water interface; 2 = surficial modifiers, restricted to the top $1-2 \mathrm{~cm}$ of the sediment; $3=$ headdown/head-up feeders actively transporting sediment to/from the surface; 4 = biodiffusers causing a random diffusive transport of particles over short distances; and $5=$ gallery diffusers. For example, the most abundant species were scored as follows (values for $M_{i}$ and $R_{i}$ respectively, in parentheses): 
Marenzelleria spp. (5, 5), Macoma balthica $(3,4)$, and Monoporeia affinis $(5,4)$.

BPI was calculated on abundance and biomass data from 3 replicate samples, each covering $0.1 \mathrm{~m}^{2}$, taken with a Van Veen grab from each station. Since the research vessel, equipped with a dynamic positioning system, was kept in exactly the same position during sampling at a station, we are confident that pigment cores and Van Veen samples were taken in close proximity to each other. We chose to calculate BPI on the Van Veen data because all species were motile on the scale of pigment cores $\left(2 \times 0.0063 \mathrm{~m}^{2}\right)$ and covered a ca. 18 times larger area, the Van Veen material would likely give a more reliable estimate of fauna abundance and biomass.

The redox potential discontinuity (RPD) was obtained by visual inspection of the cores.

\section{Pigment analyses}

Pigment extraction

A portion (1 to $3 \mathrm{~g}$ ) of homogenized freeze-dried sediment was extracted in $10 \mathrm{ml}$ cold $100 \%$ HPLC grade acetone. Samples were shaken in a minishaker and after 4 to $5 \mathrm{~h}$ were sonicated in an icebath for $15 \mathrm{~min}$ and finally extracted at $-20^{\circ} \mathrm{C}$ for approximately $20 \mathrm{~h}$ in the dark. Extracts were filtered through a $0.45 \mu \mathrm{m}$ nylon filter (CAMEO 25 GF, Frisinette). A $1 \mathrm{ml}$ sample was transferred to a $2 \mathrm{ml}$ screw top vial (BROWN) and diluted with $250 \mu \mathrm{l}$ Milli-Q water before injection to improve separation of pigments in the column. The whole procedure was conducted under dim light.

\section{HPLC analyses}

Quantitative analyses of all pigments were conducted on a Shimadzu HPLC equipped with an online photodiode array detector (SPD-M10Avp) and fluorescence detector (RF-10Axl) with excitation set at $350 \mathrm{~nm}$ and emission at $450 \mathrm{~nm}$ (for identification purposes only). Injection of $100 \mu \mathrm{l}$ was conducted using a Shimadzu SIL-10AF auto-sampler with sample cooler set at $4^{\circ} \mathrm{C}$. A reverse phase Supelcosil LC-18 column ( $5 \mu \mathrm{m}$ particle size; $25 \mathrm{~cm} \times 4.6 \mathrm{~mm}$ ID) with a guard column was used for separation. The flow rate was $0.85 \mathrm{ml} \mathrm{min}^{-1}$. The time program starts isocratically with mobile phase A (75:25 acetone:HPLC water);

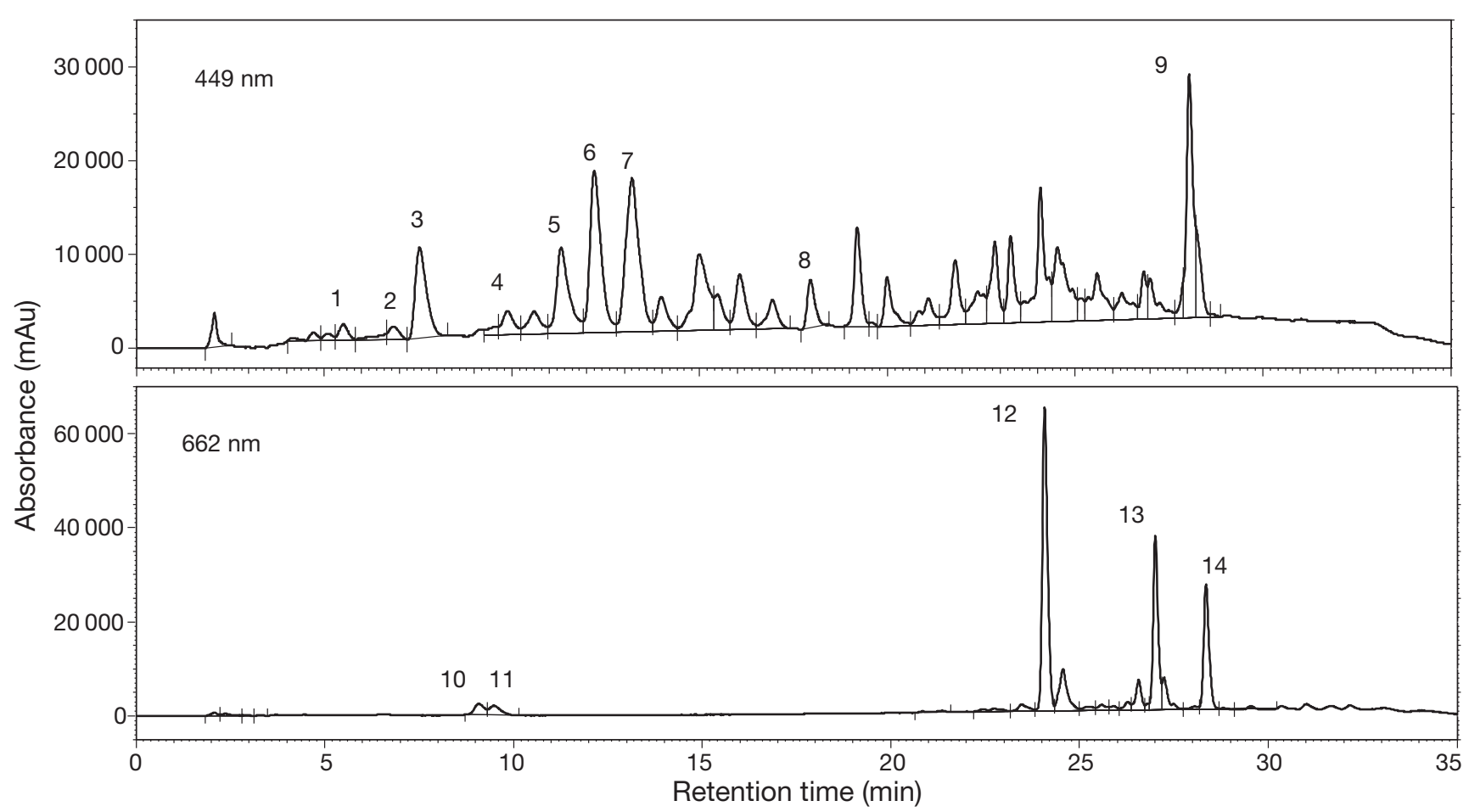

Fig. 2. Absorbance chromatograms at 2 wavelengths (449 and $662 \mathrm{~nm}$ ) from a sediment sample at 5-8 $\mathrm{cm}$ sediment depth in the Gulf of Finland (Stn GOF2). The identified pigment peaks are as follows: (1) peridinin, (2) 19'-butanoyloxyfucoxanthin, (3) fucoxanthin, (4) diadinoxanthin, (5) alloxanthin, (6) diatoxanthin, (7) zeaxanthin, (8) cantaxanthin, (9) $\beta$-carotene, (10) phaeophorbide a1, (11) phaeophorbide a2, (12) chlorophyll $a_{1}$ (13) phaeophytin $a_{1}$ (14) pyrophaeophytin $a$. Vertical lines delimit peaks of different pigments, and thin horizontal lines are peak baselines 
ramps up to $100 \%$ mobile phase B (80:20 methanol: acetone) in $20 \mathrm{~min}$ and remains isocratic for $5 \mathrm{~min}$; the gradient returns to $100 \% \mathrm{~A}$ in $2 \mathrm{~min}$.; and, finally, runs isocratically with $100 \%$ A for 7 min.

\section{Pigment identification and quantification}

All chromatograms were integrated and calculated using Class VP 7.2 software. Quantification of chl a and phaeopigments was conducted at $662 \mathrm{~nm}$ and carotenoids at $449 \mathrm{~nm}$ (Fig. 2). Identification of individual pigments (Table 1) was conducted as a combination of retention time and absorption spectra compared with authentic standards, exemplified in Appendix 1. Quantification was based on 3 to 4 point calibration curves of standards for each pigment obtained from the Danish Hydraulic Institute (DHI).

The data were transformed from $\mu \mathrm{g}$ pigment $\mathrm{g}^{-1}$ dry sediment to $\mu \mathrm{g}$ pigment $\mathrm{cm}^{-3}$ wet sediment by using the water content and an assumed specific weight of dry sediment of 2.5.

\section{Numerical analyses}

Pigment inventories expressed in $\mu \mathrm{g} \mathrm{cm}^{-2}$ for the top $16 \mathrm{~cm}$ of the sediment were calculated by trapez-integration of concentrations in $\mu \mathrm{g} \mathrm{cm}^{-3}$. Variability among pigment inventories was analysed with PCA on standardised values. Variability of pigment concentrations in relation to sub-area, sediment depth, oxygen and fauna impacts was analysed with 2-way ANCOVA, with the 2 first mentioned as fixed factors and either oxygen or BPI as co-variates. ANCOVA, ANOVA and PCA analyses were run using SYSTAT v.10 and PCA plots using Primer v.5.

\section{RESULTS}

\section{Benthic fauna communities}

The survey comprised sites in different areas of the Baltic (Fig. 1). In general, 1 to 3 species completely dominated macrofauna abundance in each area, except at sites with severe hypoxia or anoxia, which were largely devoid of macrofauna (Table 2). The Bothnian Bay sites were dominated by the burrowing crustacean Monoporeia affinis and the Bothnian Sea sites by Monoporeia affinis and to a lesser extent Pontoporeia femorata and the burrowing polychaete Marenzelleria spp. The Gulf of Finland sites were dominated by Marenzelleria spp. only and the Eastern Gotland Basin sites by the reworking bivalve Macoma balthica; the sites in the Southern Baltic were dominated by the burrowing polychaete Scoloplos armiger and at station BY2 by this species, together with Macoma balthica, Ampharete baltica and Capitella capitata. Thus, the community compositions were, to a great extent, different among areas.

\section{General pigment patterns}

Values from the individual 303 measurements of total pigments from each stratum in each core ranged from $\sim 1$ to $340 \mu \mathrm{g} \mathrm{g}^{-1}$ dry sediment or $\sim 0.2$ to $113 \mu \mathrm{g}$ $\mathrm{cm}^{-3}$ sediment. Inventories of the top $16 \mathrm{~cm}$ of the sediment of total pigments, and the sum of 12 different chloropigments and carotenoids (Tables 1 \& 3), varied considerably among different sub-areas. Lowest average values of total pigments were found in the Bothnian Bay $\left(\sim 14 \mu \mathrm{g} \mathrm{cm}^{-2}\right)$ and the highest, ca. 17 times higher, were found in the Gulf of Finland $\left(243 \mu \mathrm{g} \mathrm{cm}^{-2}\right)$. Average concentrations in the Bothnian Sea and the Baltic Proper were intermediate (ca. 55 to $75 \mu \mathrm{g} \mathrm{cm}^{-2}$ ), 3 to 4 times lower than in the Gulf of Finland. Dominating pigments were phaeopigments (phaeophytin a and pyrophaeophytin a), chl $a$, fucoxanthin, zeaxanthin and $\beta$-carotene, which together constituted 85 to $97 \%$ by weight of total pig-

Table 1. Pigments analysed and their diagnostic values. All pigments were quantified with a standard, except for phaeophorbide $a 1$ and phaeophorbide $a 2$, which were quantified by the peak area only

\begin{tabular}{|ll}
\hline Pigment & $\begin{array}{l}\text { Algal division } \\
\text { (from Jeffrey \& Vesk 1997) }\end{array}$ \\
\hline Chlorophyll a & All groups \\
及-carotene & Most groups \\
Alloxanthin & Cryptophyta \\
19'-Butanoyloxy- & Prymnesiophyceae, \\
fucoxanthin & Chrysophyceae \\
Canthaxanthin & Cyanophytes \\
Diadinoxanthin & Euglenophyta, Bacillariophyta, \\
& Dinophyta, Prymnesiophyceae, \\
& Chrysophyceae, Raphidophyceae \\
Diatoxanthin & Same groups as for Diadinoxanthin \\
Fucoxanthin & Bacillariophyta, Prymnesiophyceae, \\
& Chrysophyceae, Raphidophyceae \\
Peridinin & Dinophyta \\
Zeaxanthin & Common in Cyanophyta, \\
& Prochlorophyta, Rhodophyta \\
Phaeophytin a & Breakdown product of chl a \\
Pyrophaeophytin a & Breakdown product of chl a \\
Phaeophorbide a1 & Breakdown product of chl a \\
Phaeophorbide a2 & Breakdown product of chl a \\
\hline
\end{tabular}


Table 2. Site descriptions. Sediment accumulation rate (SAR) in $\mathrm{g}$ dry $\mathrm{wt} \mathrm{m}^{-2} \mathrm{yr}^{-1}$ (sedimentation data from outside the Gulf of Finland are taken from Mattila et al. 2006). BPI = bioturbation potential. Dominant species with percentage of abundance in experimental cores in brackets: Mar = Marenzelleria spp., Mac = Macoma balthica, $\mathrm{Scol}=$ Scoloplos armiger, Mon $=$ Monopor eia affinis (+ Pontoporeia femorata in the Bothnian Sea) and Mixed $=4$ taxa: Scoloplos, Ampharete, Macoma and Capitella. no $\mathrm{a}=$ no animals in experimental cores

\begin{tabular}{|c|c|c|c|c|c|c|c|c|c|}
\hline Site & Lat. $\left({ }^{\circ} \mathrm{N}\right)$ & Long. $\left({ }^{\circ} \mathrm{E}\right)$ & $\begin{array}{l}\text { Depth } \\
\text { (m) }\end{array}$ & $\begin{array}{c}\text { Oxygen } \\
\left(\mu \mathrm{mol} \mathrm{l}^{-1}\right)\end{array}$ & Salinity & SAR & Ind. $\mathrm{m}^{-2}$ & BPI & Dominant \\
\hline \multicolumn{10}{|c|}{ Bothnian Bay } \\
\hline BO3 & $64^{\circ} 18.12^{\prime}$ & $22^{\circ} 20.59^{\prime}$ & 108 & 391 & 3.77 & 910 & 459 & 374 & Mon (100) \\
\hline CV1 & $65^{\circ} 14.02^{\prime}$ & $23^{\circ} 33.77^{\prime}$ & 68 & 377 & 3.22 & 290 & 184 & 219 & Mon (100) \\
\hline \multicolumn{10}{|c|}{ Bothnian Sea } \\
\hline F64 & $60^{\circ} 11.34^{\prime}$ & $19^{\circ} 08.55^{\prime}$ & 286 & 310 & 7.03 & 320 & 2047 & 3308 & Mon + Mar (90) \\
\hline SR5 & $61^{\circ} 05.00^{\prime}$ & $19^{\circ} 34.78^{\prime}$ & 125 & 242 & 6.45 & 1160 & 4917 & 9331 & Mon + Mar (100) \\
\hline F18 & $63^{\circ} 18.86^{\prime}$ & $20^{\circ} 16.36^{\prime}$ & 104 & 241 & 6.10 & 5935 & 4206 & 11246 & Mon + Mar (97) \\
\hline US2 & $62^{\circ} 50.72^{\prime}$ & $18^{\circ} 53.32^{\prime}$ & 201 & 201 & 6.24 & 5250 & 2206 & 6060 & Mon + Mar (94) \\
\hline \multicolumn{10}{|c|}{ Gulf of Finland } \\
\hline GOF2 & $60^{\circ} 05.76^{\prime}$ & $25^{\circ} 18.97^{\prime}$ & 47 & 149 & 7.21 & 970 & 4269 & 9975 & Mar (96) \\
\hline GOF3 & $60^{\circ} 04.43^{\prime}$ & $25^{\circ} 19.41^{\prime}$ & 59 & 118 & 7.97 & 626 & 1587 & 3860 & Mar (100) \\
\hline GOF4 & $59^{\circ} 58.93^{\prime}$ & $25^{\circ} 10.16^{\prime}$ & 62 & 65.9 & 8.44 & 345 & 301 & 908 & Mar (100) \\
\hline GOF5 & $59^{\circ} 57.10^{\prime}$ & $25^{\circ} 11.03^{\prime}$ & 64 & 60.3 & 8.45 & 691 & 771 & 2006 & Mar (86) \\
\hline GOF6 & $59^{\circ} 56.96^{\prime}$ & $25^{\circ} 06.58^{\prime}$ & 70 & 68.1 & 9.02 & 1261 & 116 & 242 & (no a) \\
\hline \multicolumn{10}{|c|}{ Eastern Gotland Basin } \\
\hline EGB1 & $57^{\circ} 58.95^{\prime}$ & $21^{\circ} 17.00^{\prime}$ & 63 & 249 & 7.82 & & 295 & 1527 & Mac (68) \\
\hline LF1 & $57^{\circ} 58.95^{\prime}$ & $21^{\circ} 16.84^{\prime}$ & 67 & 245 & 7.92 & & 917 & 3785 & Mac (67) \\
\hline HAS & $57^{\circ} 58.97^{\prime}$ & $21^{\circ} 12.44^{\prime}$ & 72 & 173 & 8.20 & 160 & 5.95 & 8 & (no a) \\
\hline LF2 & $57^{\circ} 59.00^{\prime}$ & $21^{\circ} 05.00^{\prime}$ & 81 & 0 & 9.44 & 680 & 0 & 0 & (no a) \\
\hline \multicolumn{10}{|c|}{ Southern Baltic } \\
\hline HYPER1 & $54^{\circ} 38.98^{\prime}$ & $15^{\circ} 45.00^{\prime}$ & 61 & 70 & 13.68 & & 491 & 1914 & Scol (60) \\
\hline HYPER2 & $54^{\circ} 44.65^{\prime}$ & $15^{\circ} 45.00^{\prime}$ & 67 & 42 & 14.56 & & 62,5 & 278 & (no a) \\
\hline HBP137 & $54^{\circ} 41.00^{\prime}$ & $15^{\circ} 45.00^{\prime}$ & 64 & 49 & 14.32 & & 438 & 1553 & Scol (80) \\
\hline HBP115 & $55^{\circ} 03.00^{\prime}$ & $15^{\circ} 45.00^{\prime}$ & 86 & 40 & 15.72 & & 11.9 & 16 & (no a) \\
\hline BY5 & $55^{\circ} 15.00^{\prime}$ & $15^{\circ} 59.00^{\prime}$ & 90 & 29 & 15.89 & & 1.79 & 3 & (no a) \\
\hline BY2 & $55^{\circ} 00.00^{\prime}$ & $14^{\circ} 05.00^{\prime}$ & 47 & 242 & 15.58 & $400^{\mathrm{a}}$ & 484 & 1036 & Mixed (95) \\
\hline НРB216 & $55^{\circ} 41.00^{\prime}$ & $14^{\circ} 42.00^{\prime}$ & 80 & 48 & 15.56 & & 0 & 0 & (no a) \\
\hline BCSIII10 & $55^{\circ} 33.00^{\prime}$ & $18^{\circ} 24.00^{\prime}$ & 90 & 45 & 10.42 & 440 & 1.79 & 6 & (no a) \\
\hline
\end{tabular}

ments. Phaeophorbides were not quantified and not included in total pigments because of lack of standards. However, judging from peak areas in the chromatograms, significant levels were present mainly in surface sediments in the Bothnian Sea and Bothnian Bay.

Concentrations of total pigments showed a decrease with sediment depth mainly due to fucoxanthin and chl $a$, while zeaxanthin and $\beta$-carotene did not seem to decrease consistently with depth (Table 3). Differences in composition of total pigment inventories among sub-areas are visualised in the PCA plots of data from the $16 \mathrm{~cm}$ inventories in Fig. 3. A main pattern was that the samples within the subareas Gulf of Finland (GOF), Bothnian Sea (BS), and Bothnian Bay (BB) showed clusters that were distinguishable from each other and from a major looser cluster of the Baltic Proper. PCA analysis on inventories of 12 pigments from each of the 23 sites showed that the first and the second component explained more than $90 \%$ of the total variance. All 12 pigments had heavy positive loadings on PC1, which explained $80.5 \%$ of the variation. On the second principal component (PC2), which explained $10.1 \%$ of the variation, chl $a$ and fucoxanthin had the strongest positive loadings, and alloxanthin, $\beta$-carotene, diatoxanthin, peridinin and zeaxanthin the strongest negative loadings. As illustrated in Fig. 3a with superimposed relative values (bubbles) of chl a inventories, principal component 1 (PC1) likely represents a gradient from high (GOF) to low (BB) pigment concentrations in the Baltic Sea. Principal component 2 (PC2) likely represents a change in the proportions among different pigments, with positive loadings of chl $a$ and fucoxanthin, the latter diagnostic of diatoms, and with negative loadings including zeaxanthin and $\beta$-carotene, diagnostic of cyanobacteria. Running the PCA analysis on inventories of the same 
Table 3. Concentrations of major pigments $\left(\mu \mathrm{g} \mathrm{cm}^{-3}\right)$ expressed as means $( \pm \mathrm{SD})$ in 3 depth strata in 5 sub-areas. Inv $=$ Inventory for top $16 \mathrm{~cm}$ of the sediment $\left(\mu \mathrm{g} \mathrm{cm}^{-2}\right)$. Total pigments $=$ sum of all pigments quantified using standards

\begin{tabular}{|c|c|c|c|c|c|c|c|}
\hline $\begin{array}{l}\text { Depth strata } \\
(\mathrm{cm})\end{array}$ & Fucoxanthin & Zeaxanthin & $\beta$-carotene & Chlorophyll a & Phaeophytin a & Pyrophaeophytin a & $\begin{array}{c}\text { Total } \\
\text { pigments }\end{array}$ \\
\hline \multicolumn{8}{|l|}{ Bothnian Bay } \\
\hline $0-1$ & $0.12 \pm 0.02$ & $0.04 \pm 0.01$ & $0.01 \pm 0.00$ & $0.04 \pm 0.02$ & $0.41 \pm 0.06$ & $0.33 \pm 0.05$ & $0.97 \pm 0.16$ \\
\hline $1-3$ & $0.07 \pm 0.06$ & $0.04 \pm 0.02$ & $0.02 \pm 0.01$ & $0.08 \pm 0.09$ & $0.44 \pm 0.22$ & $0.45 \pm 0.08$ & $1.13 \pm 0.40$ \\
\hline $5-12$ & $0.01 \pm 0.01$ & $0.04 \pm 0.04$ & $0.04 \pm 0.03$ & $0.08 \pm 0.07$ & $0.43 \pm 0.24$ & $0.39 \pm 0.24$ & $1.04 \pm 0.66$ \\
\hline Inv & $0.41 \pm 0.30$ & $0.52 \pm 0.34$ & $0.42 \pm 0.30$ & $1.00 \pm 0.79$ & $5.77 \pm 2.61$ & $5.60 \pm 2.60$ & $14.2 \pm 6.99$ \\
\hline \multicolumn{8}{|l|}{ Bothnian Sea } \\
\hline $0-1$ & $2.07 \pm 1.61$ & $0.20 \pm 0.18$ & $0.05 \pm 0.04$ & $3.41 \pm 3.86$ & $0.79 \pm 0.29$ & $0.68 \pm 0.20$ & $7.84 \pm 5.26$ \\
\hline $1-3$ & $1.35 \pm 0.70$ & $0.31 \pm 0.26$ & $0.11 \pm 0.13$ & $1.82 \pm 1.10$ & $1.10 \pm 0.42$ & $0.98 \pm 0.34$ & $6.39 \pm 3.00$ \\
\hline $5-12$ & $0.23 \pm 0.16$ & $0.27 \pm 0.14$ & $0.15 \pm 0.06$ & $0.64 \pm 0.35$ & $0.94 \pm 0.31$ & $0.84 \pm 0.37$ & $3.48 \pm 1.33$ \\
\hline Inv & $7.37 \pm 3.08$ & $3.64 \pm 1.53$ & $1.82 \pm 0.58$ & $14.1 \pm 6.30$ & $13.1 \pm 3.48$ & $11.6 \pm 3.33$ & $57.9 \pm 16.9$ \\
\hline \multicolumn{8}{|c|}{ Gulf of Finland } \\
\hline $0-1$ & $5.40 \pm 2.62$ & $0.95 \pm 0.42$ & $0.61 \pm 0.14$ & $8.92 \pm 3.49$ & $2.36 \pm 0.56$ & $2.15 \pm 0.60$ & $22.4 \pm 6.31$ \\
\hline $1-3$ & $1.10 \pm 0.58$ & $1.91 \pm 0.88$ & $0.93 \pm 0.34$ & $2.91 \pm 1.01$ & $3.56 \pm 0.52$ & $3.40 \pm 0.48$ & $16.2 \pm 2.72$ \\
\hline $5-12$ & $0.57 \pm 0.57$ & $1.48 \pm 0.62$ & $0.76 \pm 0.37$ & $2.65 \pm 2.59$ & $3.92 \pm 1.53$ & $3.48 \pm 1.11$ & $14.7 \pm 7.09$ \\
\hline Inv & $14.5 \pm 7.31$ & $24.2 \pm 6.06$ & $12.2 \pm 3.13$ & $46.1 \pm 21.4$ & $60.3 \pm 12.3$ & $54.6 \pm 5.94$ & $243 \pm 58.1$ \\
\hline \multicolumn{8}{|c|}{ Eastern Gotland Basin } \\
\hline $0-1$ & $1.13 \pm 1.32$ & $0.78 \pm 0.91$ & $0.49 \pm 0.29$ & $2.52 \pm 1.77$ & $1.97 \pm 1.17$ & $1.37 \pm 0.59$ & $9.55 \pm 4.06$ \\
\hline $1-3$ & $0.61 \pm 0.70$ & $0.68 \pm 1.04$ & $0.46 \pm 0.41$ & $1.24 \pm 1.52$ & $1.70 \pm 1.06$ & $1.26 \pm 0.87$ & $7.12 \pm 5.88$ \\
\hline $5-12$ & $0.15 \pm 0.23$ & $0.68 \pm 1.07$ & $0.33 \pm 0.38$ & $0.37 \pm 0.49$ & $1.30 \pm 1.40$ & $0.83 \pm 0.80$ & $4.25 \pm 5.03$ \\
\hline Inv & $4.45 \pm 3.45$ & $10.6 \pm 16.3$ & $5.48 \pm 5.97$ & $10.0 \pm 8.21$ & $20.7 \pm 20.7$ & $14.2 \pm 12.4$ & $76.5 \pm 76.9$ \\
\hline \multicolumn{8}{|c|}{ Southern Baltic } \\
\hline $0-1$ & $1.41 \pm 1.12$ & $0.51 \pm 0.38$ & $0.35 \pm 0.15$ & $0.81 \pm 0.38$ & $1.02 \pm 0.49$ & $0.88 \pm 0.39$ & $5.98 \pm 3.06$ \\
\hline $1-3$ & $1.00 \pm 1.04$ & $0.60 \pm 0.43$ & $0.45 \pm 015$ & $0.55 \pm 0.25$ & $1.30 \pm 0.48$ & $1.14 \pm 0.35$ & $5.92 \pm 3.02$ \\
\hline $5-12$ & $0.28 \pm 0.30$ & $0.37 \pm 0.24$ & $0.31 \pm 0.14$ & $0.41 \pm 0.32$ & $1.02 \pm 0.51$ & $0.84 \pm 0.39$ & $3.74 \pm 1.92$ \\
\hline Inv & $6.62 \pm 4.77$ & $6.10 \pm 3.86$ & $4.96 \pm 1.92$ & $6.52 \pm 3.84$ & $15.8 \pm 6.9$ & $13.3 \pm 4.8$ & $62.2 \pm 28.7$ \\
\hline
\end{tabular}

pigments, together with the BPI, gave a similar result for pigments as in Fig. 3, and BPI had heavy positive loading (0.9) on PC2 (Fig. 4). Running the pigments together with Marenzelleria abundance instead of BPI (analysis not shown) gave a similar result as with $\mathrm{BPI}$, suggesting that much of the covariation between PC2 and BPI was due to Marenzelleria.

Diatom material, indicated by high concentrations of fucoxanthin, was abundant in the Bothnian Sea and the parts of the Gulf of Finland that also had high fauna abundance, but also at some sites in the southern Baltic (Fig. 3b).

Zeaxanthin, a marker of cyanobacteria, showed high concentrations in the Gulf of Finland and parts of the Baltic Proper (such as the Eastern Gotland Basin area) and was virtually absent in Bothnian Bay (Fig. 3c).

\section{Oxygen gradients and BPI}

Oxygen clearly regulates the benthic fauna and thereby the bioturbation potential (Fig. 5). The relation assessed with LOWESS smoothing indicates a threshold at 45 to $90 \mu \mathrm{mol} \mathrm{l}^{-1}$ oxygen. Between anoxic conditions up to the threshold the BPI increases more than 3 orders of magnitude and then levels off. Therefore, in order to evaluate effects of oxygen level and associated BPI on pigments, we analysed data from areas which included sites with oxygen concentrations both above and below the threshold of $90 \mathrm{umol}^{-1}$, i.e. all areas except the Bothnian Sea and Bothnian Bay (Fig. 1, Table 2).

A 2-way ANCOVA with area (Gulf of Finland, Eastern Gotland Basin, and Southern Baltic, df $=2$ ) and sediment strata $(0-1,1-3$, and $5-12 \mathrm{~cm}$ strata, $\mathrm{df}=2$ ) as fixed factors, and with either oxygen concentration or BPI as covariate, was used to test for effects on major pigments (interaction area $\times$ stratum, $\mathrm{df}=4$, and error for most pigments, $\mathrm{df}=155$ ). To normalise data distributions, BPI was $\log _{10}(x+1)$ transformed, and the pigments were $\log _{10}(x)$ transformed. We tested for effects on the following pigments (in $\mu \mathrm{g} \mathrm{cm}^{-3}$ ): total pigments (= sum of all quantified 12 pigments); chl $a$ equivalents $(=\operatorname{chl} a+$ phaeophytin $a+$ pyrophaeophytin a); fucoxanthin; zeaxanthin; $\beta$-carotene; and chl a alone. We also tested for effects on the ratio between $\mathrm{chl} a$ and phaeophytin $a+$ pyrophaeophytin $a$, which in the following is denoted chl a:phaeophytin ratio. There 

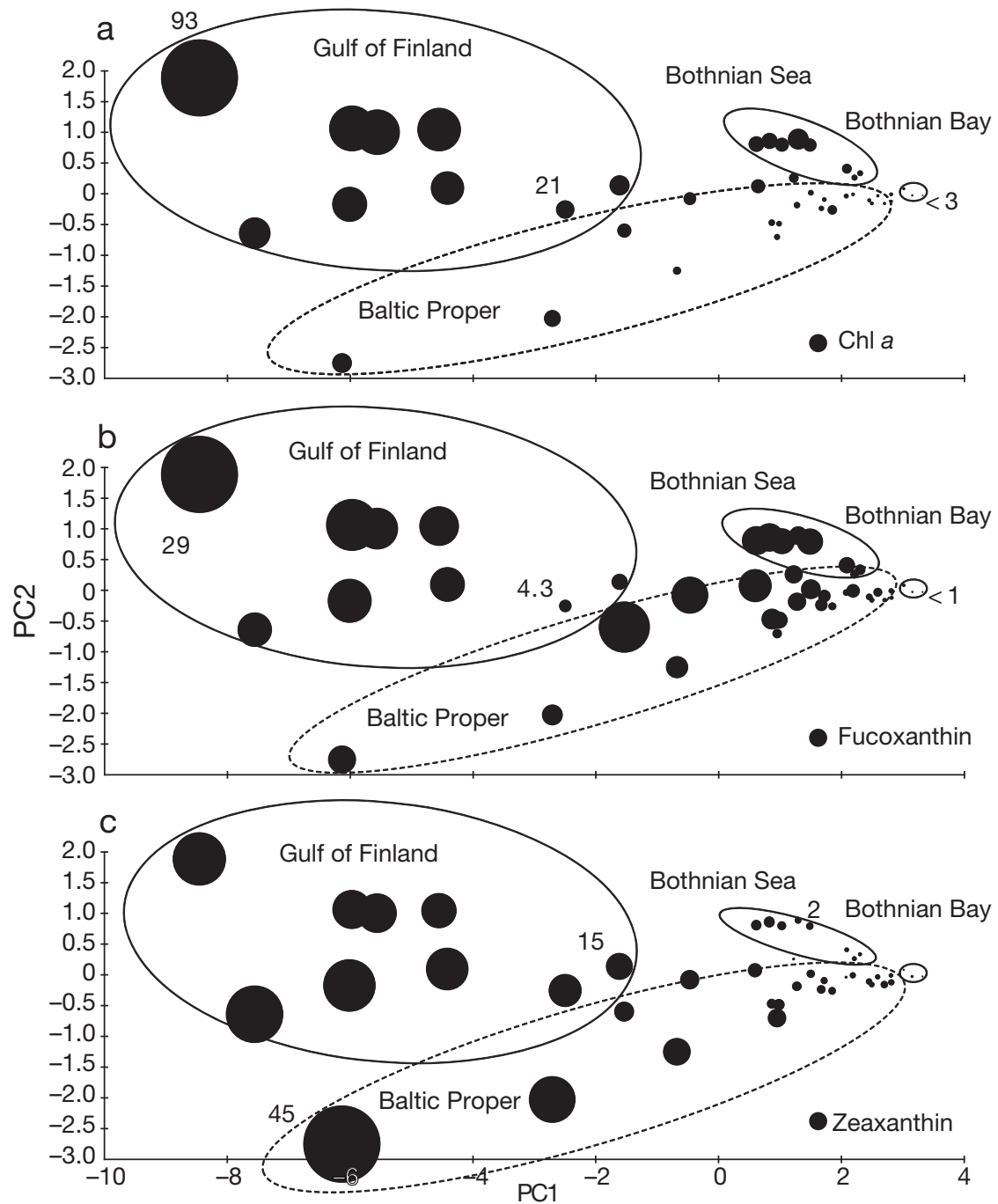

Fig. 3. PCA plots of pigment samples in relation to PC1 and PC2 together explaining $>90 \%$ of the variation in inventories of 12 different pigments (top $16 \mathrm{~cm}$ of the sediment). Sizes of superimposed bubbles relate positively to inventory concentrations of (a) chlorophyll $a_{1}$ (b) fucoxanthin, and (c) zeaxanthin. Values $\left(\mu \mathrm{g} \mathrm{cm}^{-2}\right)$ are given for scale where $<3$ and $<1$ refer to data points (circles) within the smallest ellipses which delimit data from the Bothnian Bay. Sub-areas within the Baltic Proper (Eastern Gotland and Southern Baltic) were too similar to allow graphical separation
In 2 of the 3 areas with steep oxygen gradients, the relations between total pigments and BPI were negative in all 3 sediment strata; that is, higher pigment concentrations occurred when BPI was low (Fig. 6). This was also the case for BPI in the top $3 \mathrm{~cm}$, i.e. the dwelling zone of Monoporeia and Pontoporeia in the well-oxygenated Bothnian Sea (Fig. 7). There were significant negative correlations between logarithmic values of BPI and total pigments $(\mathrm{r}=-0.63, \mathrm{p}=$ $0.001, \mathrm{n}=23$ ) and BPI and chl a concentrations $(\mathrm{r}=-0.53, \mathrm{p}=0.009$, $\mathrm{n}=23$ ). There were also strong correlations between abundance values of Monoporeia + Pontoporeia from individual cores with both total pigments and chl $a(\mathrm{r}=-0.64, \mathrm{p}<0.01, \mathrm{n}=23$ for both measures), but not with abundance of the co-occurring Marenzelleria spp. $(\mathrm{r}=-0.45, \mathrm{p}<0.05$ and $\mathrm{r}$ $=-0.31, \mathrm{p}>0.05$ for total pigments and chl $a$, respectively, $\mathrm{n}=23$ ). This indicated a main effect on degradation by the crustaceans. However, in the Gulf of Finland, where the crustaceans were absent, there was positive co-variation between pigment concentrations in the $5-12 \mathrm{~cm}$ stratum in the sediment and both oxygen and BPI (with BPI in Fig. 6), indicating a burial effect by the fauna. There were significant positive correlations between the chl a:phaeophytin ratio, a measure of 'freshness' of the material, and most pigments in the $5-12 \mathrm{~cm}$ stratum and fauna abundance, oxygen, and bioturbation potential at the GOF transect (Table 4). Virtually all of

were highly significant differences among areas for all pigments $(\mathrm{p}<0.001)$ and among strata for all $(\mathrm{p}<$ 0.001 ) except for zeaxanthin ( $p>0.05)$. A significant interaction term $(p<0.05)$ suggested that change among strata differed among areas, except for fucoxanthin which showed similar change with strata in most areas, as indicated by a non-significant interaction term $(p>0.05)$. Results with either covariate, oxygen or BPI, were similar and significant $(p<0.01$ for fucoxanthin and $\mathrm{p}<0.001$ for the remaining pigments), while there was no co-variation with the chl a:phaeophytin ratio ( $\mathrm{p}>0.05)$. the macrofauna individuals at this transect belonged to the burrowing polychaete Marenzelleria spp., and the water content of the sediment was regressed against number of Marenzelleria individuals to confirm if Marenzelleria burrows, some visible close to the glass in the periphery of the cores, reached into the 5-12 cm stratum (Fig. 8). There was a very significant $(p<0.01)$ positive relation between water content at 5-12 $\mathrm{cm}$ and number of individuals, supporting the expectation that the burrows indeed reached into this stratum. This enrichment of pigments at the GOF sites may have con- 


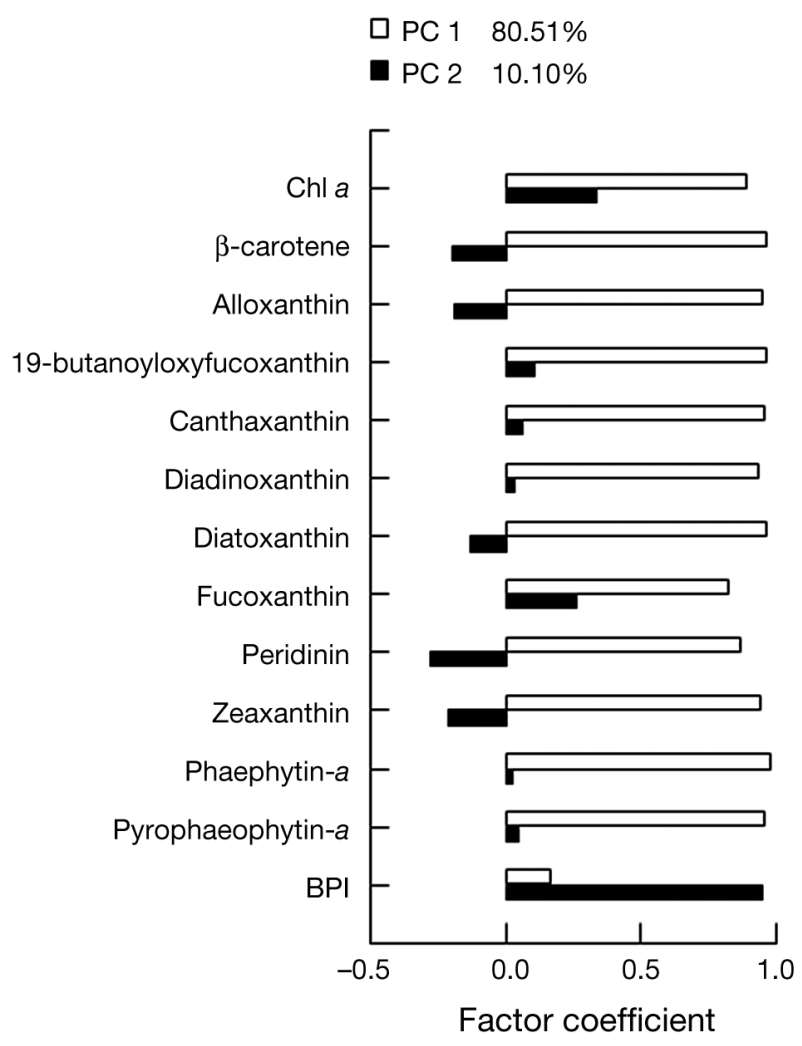

Fig. 4. Factor loading plot from PCA analysis of 12 pigments and bioturbation potential (BPI) on the PC1 and PC2

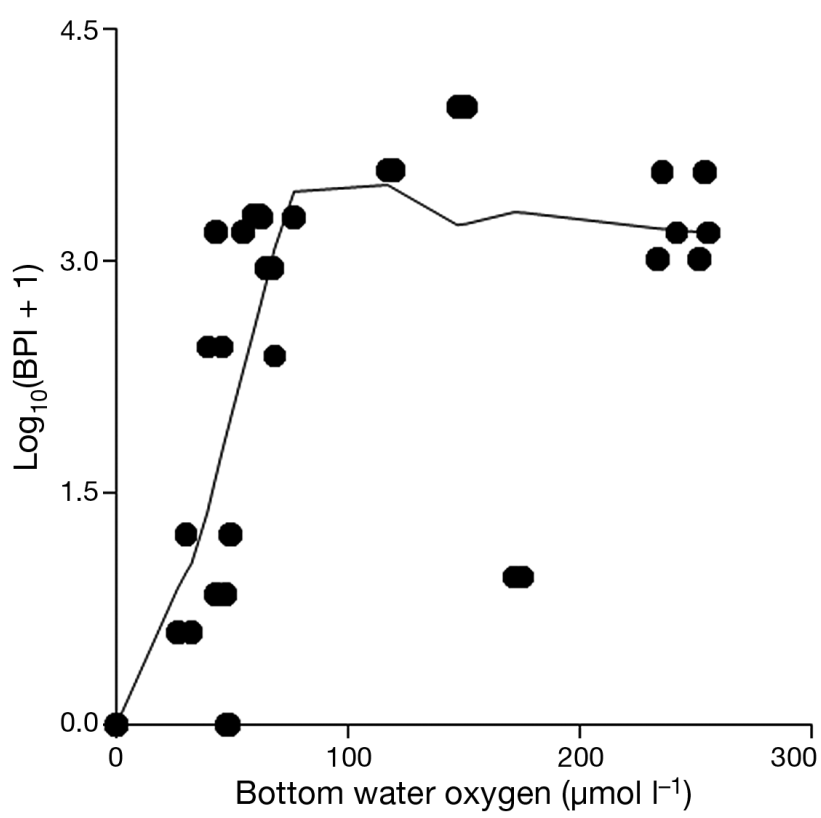

Fig. 5. Relationship between bioturbation potential (BPI) and the near-bottom water oxygen concentration in the 3 subareas with strong oxygen gradients. Regression line obtained from LOWESS smoothing (tension 0.6). The low BPI value at ca. $170 \mu \mathrm{mol} \mathrm{l}^{-1}$ represents a site that had been anoxic the previous year, i.e. the fauna had not yet recovered tributed to some of the variation along $\mathrm{PC} 1$, and in particular PC2, in the PCA analysis, including pigments and BPI, where PC2 explained ca. $10 \%$ of the variation. The BPI, to a great extent determined by Marenzelleria abundance, varied positively with chl $a$ and fucoxanthin along PC2 (Fig. 4).

\section{Grazing effects and breakdown products of chlorophyll a}

The relative importance of formation of the chl a breakdown products phaeophorbide a (2 forms) and phaeophytin $a$ and pyrophaeophytin a was assessed by the phaeophorbide:phaeophytin ratio, where the sum of peak areas of the phaeophorbides was divided by the sum of the peak areas of phaeophytin and pyrophaeophytin. Values in the top $\mathrm{cm}$ and the 1-3 cm segments were significantly elevated, with ratios close to 1, in the Bothnian Sea (BS) and Bothnian Bay (BB) areas compared to the Gulf of Finland (GoF), Eastern Gotland Basin (EB) and Southern Baltic (SB) areas tested with ANOVA and LSD (least significant difference pairwise multiple comparison test) (Fig. 9a; for 0-1 cm ANOVA: $F_{5,43}=17.12, \mathrm{p}<0.001, \mathrm{LSD}: \mathrm{BH}>$ all other areas, $\mathrm{p}<0.05$, and $\mathrm{BB}>\mathrm{EB}$ and SB, $\mathrm{p}<0.05$ ) (Fig. 9b; for 1-3 cm ANOVA: $F_{5,88}=47.48, \mathrm{p}<0.001$, LSD: $\mathrm{BB}$ and $\mathrm{BH}>$ all other areas, $\mathrm{p}<0.001)$. In the deeper segment $(5-12 \mathrm{~cm})$, ratios were around 0.2 in most areas and even lower in Bothnian Bay (Fig. 9C; ANOVA $F_{5,87}=7.94, \mathrm{p}<0.001, \mathrm{LSD}: \mathrm{BB}<$ all other areas, $\mathrm{p}<0.001)$. High values occurred only in the top $3 \mathrm{~cm}$ of the sediment in areas with the crustaceans Monoporeia and Pontoporeia, and there were significant positive Pearson correlations between the combined abundance of these 2 species and the ratios in the top $3 \mathrm{~cm}(0-1 \mathrm{~cm}: \mathrm{r}=0.45$, $\mathrm{p}=0.003, \mathrm{n}=43 ; 1-3 \mathrm{~cm}: \mathrm{r}=0.77, \mathrm{p}<0.001, \mathrm{n}=$ $88)$, while this correlation was negative in the deep segment $(5-12 \mathrm{~cm}: \mathrm{r}=-0.38, \mathrm{p}<0.001, \mathrm{n}=87)$.

\section{DISCUSSION}

Pigment distributions differed between areas in the Baltic Sea depending on oxygen concentrations, macrofaunal composition, and bioturbation potential. Our working hypotheses/expectations, however, were only partly fulfilled due to speciesspecific effects of macrofauna on pigment levels and distributions in the sediment. Experiments in soft sediments have often found that only a small part of 
Gulf of Finland
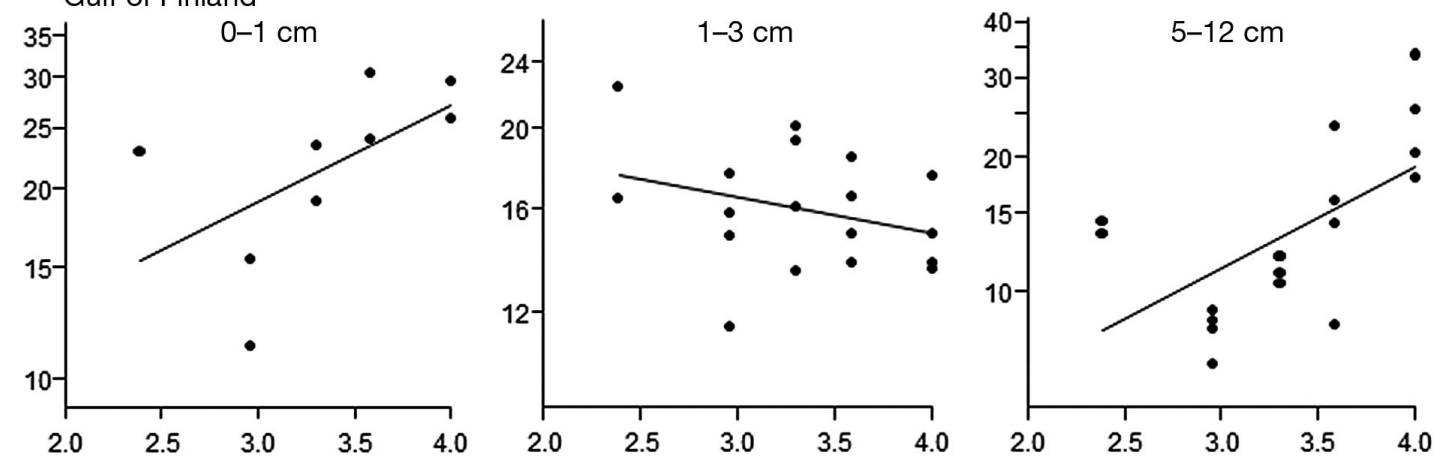

Eastern Gotland Basin
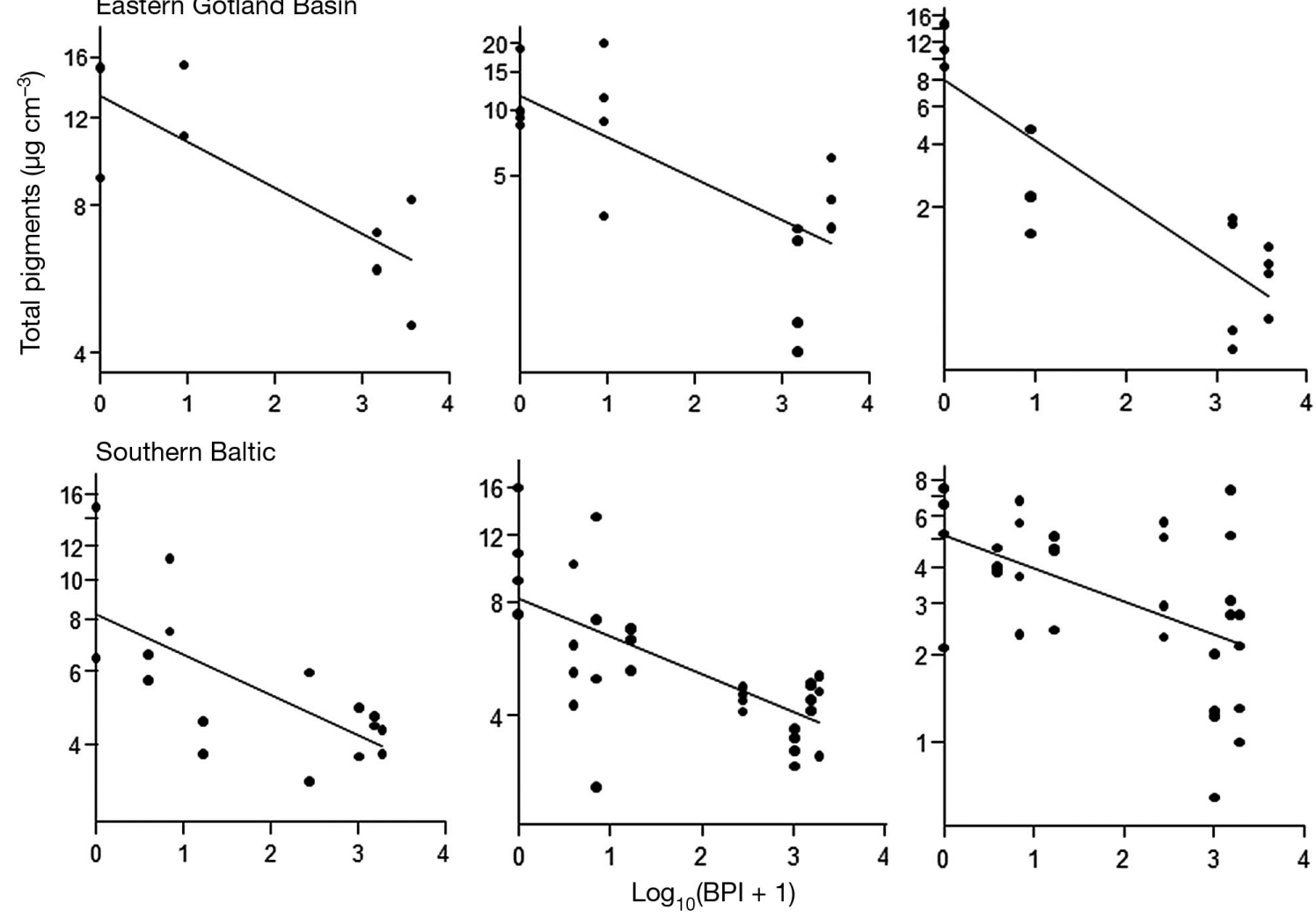

Fig. 6. Plots of total pigment concentrations (sum of 12 pigments) versus bioturbation potential (BPI) from 3 sediment strata at the 3 sub-areas with steep oxygen gradients: Gulf of Finland, Eastern Gotland Basin, and Southern Baltic

Bothnian Sea
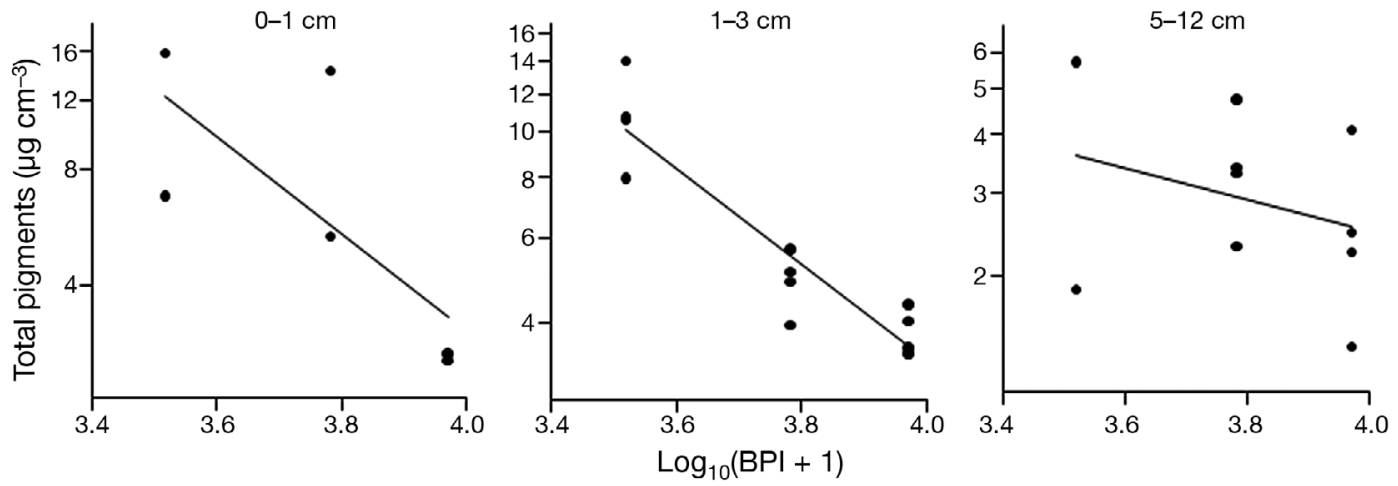

Fig. 7. Plots of total pigment concentrations (sum of 12 pigments) versus bioturbation potential (BPI) from 3 sediment strata in the Bothnian Sea 
Table 4. Results of Pearson product moment correlation analysis between 16 variables (12 related to pigments, $\mathrm{n}=18 ; 2$ measurements in each of 9 cores; and 4 environmental variables) from the 5-12 cm sediment stratum at sites in the Gulf of Finland transect ( $\mathrm{r}=$ Pearson product moment coefficient, $\mathrm{p}=$ Bonferroni corrected probabilities). Results are only shown for pigments (and RPD) that have a significant $(\mathrm{p}<0.05)$ correlation with at least one environmental variable (significant coefficients in bold). RPD = lower border of oxidized zone (biogenic mixing zone, $\mathrm{n}=9$ ), BPI = bioturbation potential $(\mathrm{n}=5$ sites), TOTIND = total number of macrofauna individuals (all Marenzelleria) in experimental cores $(\mathrm{n}=9$ ), OXY = oxygen concentration in bottom water at the sites $(n=5)$

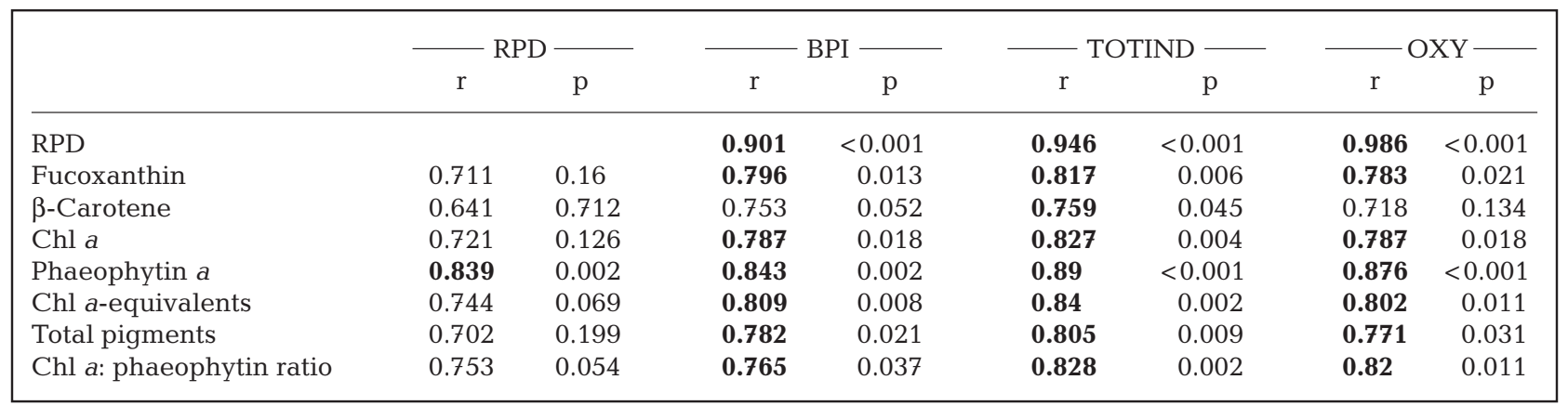
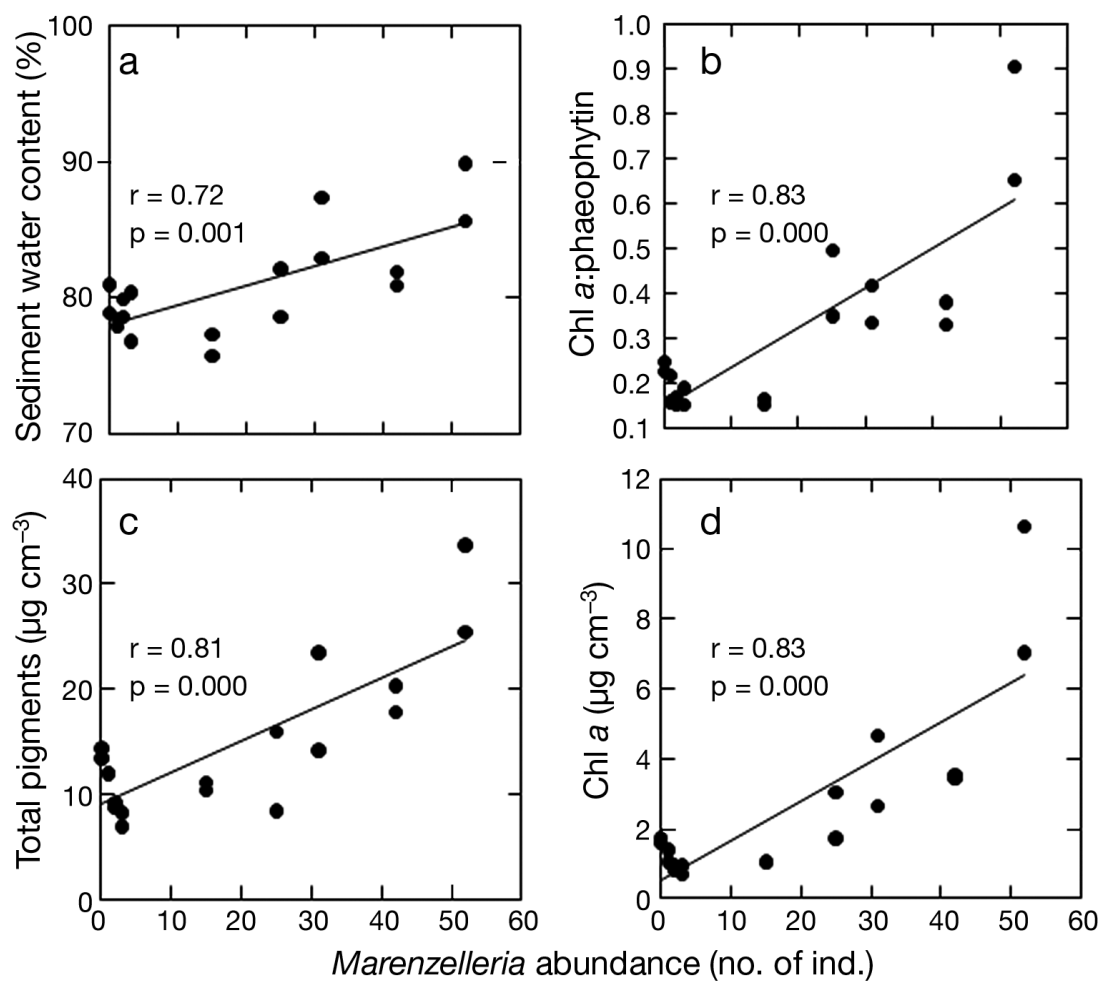

Fig. 8. Plots of (a) sediment water content, (b) chl a:phaeophytin ratio, (c) total pigments (sum of 12 pigments) and (d) chlorophyll a only in the 5-12 cm stratum versus number of individuals of Marenzelleria spp. in individual cores at the Gulf of Finland transect

labelled phytoplankton is assimilated by macrofauna and that the major part stayed in the sediment for up to several months, suggesting that gut passage is of minor importance for transformation of phytoplankton (e.g. Andersen \& Kristensen 1992, Widbom \& Frithsen 1995). We therefore assume that most of these effects were due to animal activities such as irrigation and burial, although fauna feeding likely produced phaeophorbides in the Bothnian Sea and Bothnian Bay.

\section{Hypothesis (1): Levels and composition of pigments differ between areas}

There were great differences among areas both in terms of concentration and pigment composition. A positive covariation among inventories of all different pigments (but not the BPI) along PC1 explained close to $90 \%$ of the horizontal variation of pigment suite inventories, possibly reflecting a geographical gradient in phytoplankton inputs to the bottoms. PP differs 

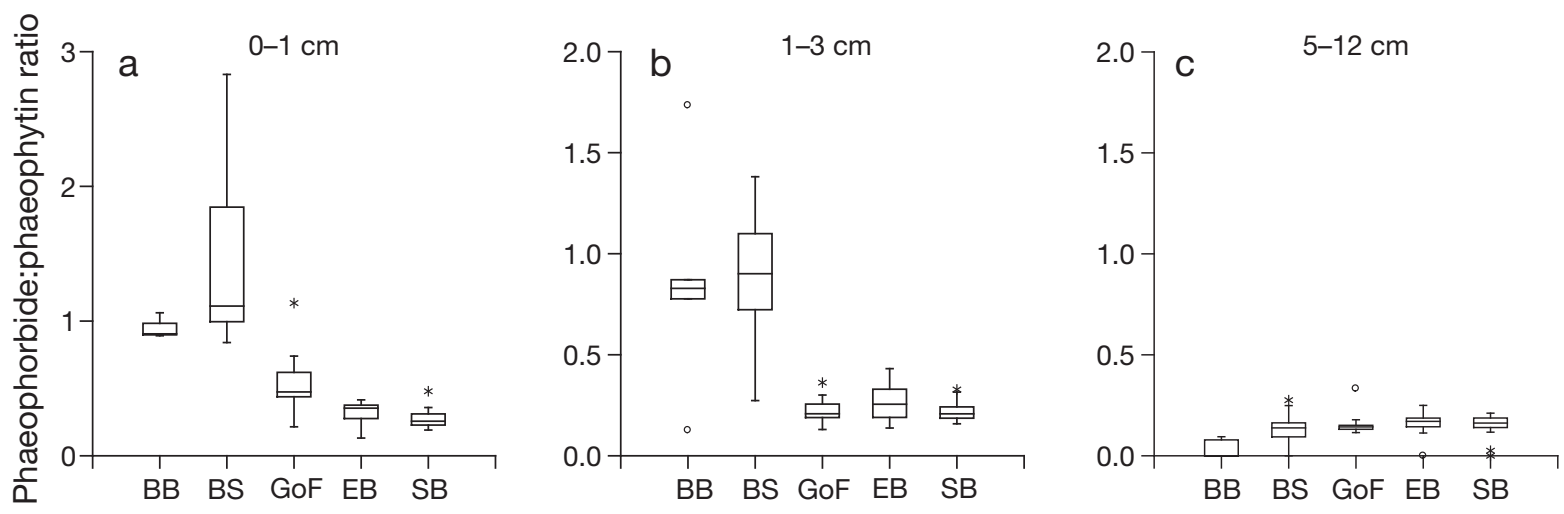

Fig. 9. Box plots of the phaeophorbide:phaeophytin ratio for 3 strata in each sub-area. BB = Bothnian Bay, BS = Bothnian Sea, $\mathrm{GoF}=$ Gulf of Finland, EG = Eastern Gotland Basin, and SB = Southern Baltic. Horizontal lines in boxes represent median values, boxes enclose data in the interquartile range (IQR), whiskers show the range of values that fall within the lower box edge $(-1.5 \mathrm{IQR})$, and the upper box edge (+1.5 IQR). Asterisks denote data outside this range and circles further outside this range

among different sub-areas in the Baltic Sea (e.g. Wasmund et al. 2001, Sandberg 2007 and references therein, Leipe et al. 2011), with the highest production in the Baltic Proper, followed by the Gulf of Finland, the Bothnian Sea and the lowest in Bothnian Bay. We observed a similar order of sediment pigment concentration levels among these areas, albeit with the highest levels in the Gulf of Finland, suggesting that some of the geographical gradient in pigment concentrations is indeed due to differential inputs of phytoplankton debris to the bottoms. However, some differences in pigment levels between areas appeared much greater than those for primary production; in particular, levels at the Gulf of Finland sites compared to the other areas. For instance, while PP was 1.4 to 2 times higher in the Gulf of Finland than in the Bothnian Sea (Sandberg 2007, Leipe et al. 2011), the total pigment inventory level was 4.2 times higher in the Gulf of Finland, which showed the highest level (Table 3).

High zooplankton grazing could be a cause of low sedimentation of fresh phytoplankton debris, but area-specific differences in the importance of zooplankton grazing are not known. As expected, the concentrations of zeaxanthin were much higher in the Baltic Proper and the Gulf of Finland than in the Bothnian Sea and Bothnian Bay, which likely reflected less cyanobacteria blooms in the latter 2 sub-areas, in agreement with previous observations of pelagic blooms (HELCOM 2009).

\section{Hypothesis (2): Pigment levels and distributions are influenced by oxygen availability and macrofauna bioturbation}

As expected from previous work (e.g. Diaz \& Rosenberg 1995), the availability of bottom-water dissolved oxygen influenced the presence of macrobenthic fauna and thereby the bioturbation potential in a threshold fashion. Below a threshold of 45 to $90 \mu \mathrm{mol} \mathrm{l}^{-1} \mathrm{O}_{2}$, BPI decreased rapidly to zero (Fig. 5). If oxygen and BPI had an effect on pigment levels, we would expect higher levels of pigments in low oxygen environments due to slower degradation of organic matter in anoxic environments.

Results from sub-areas with oxygen gradients showed that sediment concentrations of most pigments vary significantly with oxygen concentration in the bottom water as well as with the BPI, with negative relations between concentrations of pigments and oxygen concentrations and BPI in all sediment strata in 2 of the sub-areas. There was also a significant decrease in pigments with increasing BPI in the well-oxygenated Bothnian Sea and a strong negative relation between Monoporeia + Pontoporeia abundance and pigment levels in the top $3 \mathrm{~cm}$ of the sediment. Thus, it is likely that a large proportion of the increased degradation rates in oxygenated environments is due to bioturbation and feeding by benthic organisms.

\section{Hypothesis (3): Effects of fauna on pigments differ among fauna communities (sub-areas)}

Bioturbation may result in more oxygenated conditions deep in the sediment, and if this is the case, degradation of buried matter will take place quickly. However, if the material is buried in layers with little or no oxygen, degradation will be slower. Sun \& Dai (2005) showed experimentally that burial of phytoplankton material without oxygenation resulted in slow degradation, whereas burial in irrigated sediment resulted in rates as fast as at the sedimentwater interface. 
While the relation between pigments and BPI as well as oxygen was negative in most sub-areas, it was positive at the GOF transect, in the surface 0-1 cm and, in particular, in deeper strata $(5-12 \mathrm{~cm})$. Thus, results indicate that effects of bioturbation and oxygen differ among fauna communities. In communities dominated by Macoma balthica, Scoloplos armiger or Monoporeia, bioturbation increases degradation of pigments, whereas in monocultures of Marenzelleria, as found at the GOF transect, burial is a main effect. Although bioirrigation by Marenzelleria brings some oxygenated water deeper into the sediment, the irrigation rate does not appear to be fast enough to accelerate the pigment degradation in the deeper parts of the burrows; this is in agreement with Quintana et al. (2011). A rapid decrease of pigments with increasing BPI in Macoma-dominated communities is in agreement with the findings of Viitasalo-Frösén et al. (2009) who showed that Macoma decreased organic matter content in the sediment and of Karlson et al. (2005) who showed experimentally that Macoma increased mineralization by intensive mixing. This effect is likely a combination of bioturbation and deposit feeding, but since the material was relatively fresh, bioturbation was probably the main factor. In addition, Macoma is less efficient in assimilating phytodetritus compared with, for example, Monoporeia (Karlson et al. 2010).

Previous experimental work has reported that, to some extent, different breakdown products are formed from chl a by metazoan and protozoan grazing. While phaeophytins may be formed both by protozoan and metazoan grazing, phaeophorbides seem to result mainly from metazoan grazing (Bianchi et al. 1988, 2000). The present findings of extensive phaeophorbide formation, mainly in the dwelling zone of abundant Monoporeia and Pontoporeia, support this hypothesis, although it cannot be excluded that some phaeophorbide formation in the Bothnian Sea and Bothnian Bay may result from grazing by pelagic copepods. However, these compounds do not seem to be abundant in the other areas, which also have copepods. At the same time, these findings indicate that effects of metazoan grazing vary among taxa. For instance, phaeophorbide formation seemed modest at the Gulf of Finland sites despite high abundance of the metazoan Marenzelleria, which is also likely to feed on phytodetritus (Karlson et al. 2011).

The Gulf of Finland sites, where relationships between pigment concentrations and BPI in the top $1 \mathrm{~cm}$ and in the 5-12 cm strata were positive, were dominated by the burrowing polychaete Marenzelleria spp. Two non-native species of Marenzelleria are common in the northern Baltic Sea: M. neglecta and M. arctia (Blank et al. 2008). Monitoring data does not differentiate between them, as identification based on morphological characteristics is difficult. In the southern Baltic, M. viridis is more common (in shallower areas and sandier sediments). Although there are likely to be functional differences between these species, here we hypothesise generally that the increased pigment levels in the 5-12 cm stratum are due to downward non-local particle transport or burial by Marenzelleria, i.e. a transport of phytodetritus particles originating from phytoplankton. The hypothesis is supported by the following observations:

(1) If elevated pigment levels at depth resulted from high sedimentation alone this should be reflected by measurements of high sedimentation at the actual sites. This is not the case; on the contrary, sedimentation rates from $\mathrm{Pu}$ and $\mathrm{Cs}$ dating indicate lower rates than in several other areas (Mattila et al. 2006, our Table 2) and POC accumulation rates in the area of the GOF sites are not particularly high compared to most other areas (Leipe et al. 2011).

(2) Active non-local, downward transport of phytodetritus is supported by a high chl a:phaeophytin ratio, several values indicative of relatively fresh material deeper in the sediment and, in fact, nearly as high as at the sediment surface.

(3) Marenzelleria make irrigated burrows, often Lshaped, that frequently reach deeper than 5-10 cm into the sediment (Zettler et al. 1994). Burrowing by $M$. viridis considerably increases the hydrological connectivity in the sediment (Dale \& Miller 2008). The water content of the sediment at $5-12 \mathrm{~cm}$ in the sediment of the GOF sites was high and sometimes higher than at the sediment surface, which could be explained by the L-shape of the burrows. Moreover, there was a highly significant positive correlation between Marenzelleria abundance and water content (= hydrological connectivity), which suggests that Marenzelleria burrows do occur in the $5-12 \mathrm{~cm}$ stratum. This was also supported by visual observations of deep burrows in the cores sampled for pigment analyses.

(4) There are highly significant positive correlations between values from the $5-12 \mathrm{~cm}$ stratum in the same individual cores of Marenzelleria abundance and most phytopigments and also with the chl a:phaeophytin ratio, a measure of 'freshness' of the material.

(5) PCA showed a component of co-variation between chl a, fucoxanthin, oxygen and Marenzelleria abundance.

(6) As pointed out under Hypothesis 1 (see beginning of 'Discussion'), pigment inventory concentra- 
tions in the GOF area are much higher than expected from proportional sedimentation of primary production.

Thus, results are in accordance with the hypothesis that Marenzelleria is a vector of reactive phytoplankton carbon to deeper sediment layers, although the exact mechanism is not known. Most other studies of Marenzelleria impact on the sediment have focussed on irrigation and not on particle relocation (e.g. Granberg et al. 2008 for M. neglecta, Viitasalo-Frösén et al. 2009 for Marenzelleria spp. and Kristensen et al. 2011, Quintana et al. 2011 for M. viridis). Hedman et al. (2008) showed experimentally that Marenzelleria spp. may bury the metal $\mathrm{Cd}$, in particular when combined with phytoplankton detritus. Their interpretation was that $\mathrm{Cd}$ was brought to depth in the sediment in a free form by irrigation currents into the burrows. It is possible that some organic particles are transported passively with irrigation currents down into the burrows. There are, however, to our knowledge, no studies actually measuring accumulation of phytoplankton organic matter in Marenzelleria burrows. Quintana et al. (2007), however, reported both irrigation and particle transport (mixing) by $M$. viridis in experiments with sandy sediments, and recently Karlson et al. (2011) reported that $M$. arctia may bury a large part of added spring-bloom material in the sediment. Rapid subduction of fresh phytoplankton detritus to deeper sediment layers has been reported for maldanid polychaetes (Levin et al. 1997) and the ophiuroid Amphiura filiformis (Josefson et al. 2002). Whether the mechanism of subduction is hoeing, as described for the maldanids, and/or a more passive transport with irrigation water currents into the burrows, is not known. Recent studies show that the different Marenzelleria species may have different effects on sediment biogeochemistry (Kristensen et al. 2011, Norkko et al. 2012), but it is likely that the main reason for these differences is species-specific habitat preferences (i.e. $M$. viridis is more common in sandy habitats). In the current study the main point is, however, that $M$. arctia and $M$. neglecta in muddy sediments can both mix pigments into the sediment through bioturbation and bring oxygenated water into the sediment through bioirrigation. Nevertheless, future studies should more explicitly take habitat-specific and species-specific effects into account.

\section{Implications}

One way in which hypoxia may affect bioturbation and carbon cycling in the Baltic Sea is by inducing species (and abundance) shifts. The enriching function exhibited by Marenzelleria is new to the Baltic Sea system and implies that increased dominance of Marenzelleria will have significant effects on carbon cycling and oxygen dynamics in the Baltic Sea (cf. Norkko et al. 2012). Tolerance towards low oxygen differs between species, and Marenzelleria, being a polychaete, is more tolerant (Schiedek 1997) than, for instance, the crustaceans Monoporeia and Pontoporeia. Therefore, increased hypoxic conditions in the Baltic Sea will likely promote dominance of Marenzelleria in several areas. A shift from Monoporeiadominated to Marenzelleria-dominated communities has already been observed, for instance in areas of the Gulf of Finland (Maximov 2011). In the light of the present findings, a likely implication of such a shift is a build-up of the organic pool in sub-surface sediments and, although microbial activities like sulphate reduction and methanogenesis will increase, overall mineralization rates are likely to decrease and thus counteract hypoxia formation in the bottom waters. At the same time, temporary burial of reactive matter will counteract the irrigation effects of Marenzelleria because buried material during decomposition, although slow, will use oxygen deep in the burrows.

Previous, mainly experimental work in meso- and microcosms, has indicated that oxic degradation is faster than anoxic degradation, and that macrofauna may affect degradation rates as well as burial rates of fresh OM by means of bioturbation, i.e. irrigation, particle relocation, ingestion and metabolism. Our results constitute one of few field verifications of the net results from these processes in a natural setting in general, and the Baltic Sea in particular. They highlight not only the important role of macrofauna for carbon cycling in this system but also the fact that species differences matter for the outcome of bioturbation.

Acknowledgements. This work was supported by the EUBONUS+ programme project HYPER and the Academy of Finland (project nos. 114076 and 110999). Thanks go to the scientific crew of RV 'Aranda' from which sampling was conducted, to J. Gammal for help with sample collection and to B. L. Møller for HPLC analyses of pigments. Constructive comments by 2 anonymous reviewers improved the manuscript.

\section{LITERATURE CITED}

Abele-Oeschger D (1991) Potential of some carotenoids in two recent sediments of Kiel Bight as biogenic indicators of phytodetritus. Mar Ecol Prog Ser 70:83-92

Andersen FØ, Kristensen E (1992) The importance of benthic macrofauna in decomposition of microalgae in a coastal marine sediment. Limnol Oceanogr 37:1392-1403 
Bianchi TS, Dawson R, Sawanwong P (1988) The effects of macrobenthic deposit-feeding on the degradation of chloropigments in sandy sediments. J Exp Mar Biol Ecol 122:243-255

Bianchi TS, Demetropoulos A, Hadjichristophorou M, Argyrou M, Baskaran M, Lambert C (1996) Plant pigments as biomarkers of organic matter sources in sediments and coastal waters of Cyprus (eastern Mediterranean). Estuar Coast Shelf Sci 42:103-115

Bianchi TS, Johansson B, Elmgren R (2000) Breakdown of phytoplankton pigments in Baltic sediments: effects of anoxia and loss of deposit-feeding macrofauna. J Exp Mar Biol Ecol 251:161-183

Bianchi TS, Rolff C, Widbom B, Elmgren R (2002) Phytoplankton pigments in the Baltic Sea seston and sediments: seasonal variability, fluxes, and transformations. Estuar Coast Shelf Sci 55:369-383

> Blank M, Laine AO, Jürss K, Bastrop R (2008) Molecular identification key based on PCR/RFLP for three polychaete sibling species of the genus Marenzelleria, and the species' current distribution in the Baltic Sea. Helgol Mar Res 62:129-141

Boon AR, Duineveld GCA (1998) Chlorophyll a as a marker for bioturbation and carbon flux in southern and central North Sea sediments. Mar Ecol Prog Ser 162:33-43

> Dale RK, Miller DC (2008) Hydrologic interactions of infaunal polychaetes and intertidal groundwater discharge. Mar Ecol Prog Ser 363:205-215

Diaz RJ, Rosenberg R (1995) Marine benthic hypoxia: a review of its ecological effects and the behavioural responses of benthic macrofauna. Oceanogr Mar Biol Annu Rev 33:245-303

> Finni T, Kononen K, Olsonen R, Wallström K (2001) The history of cyanobacterial blooms in the Baltic Sea. Ambio 30:172-178

> Granberg ME, Gunnarsson JS, Hedman JE, Rosenberg R, Jonsson P (2008) Bioturbation-driven release of organic contaminants from Baltic Sea sediments mediated by the invading polychaete Marenzelleria neglecta. Environ Sci Technol 42:1058-1065

Hagström Å, Azam F, Kuparinen J, Zweifel UL (2001) Pelagic plankton growth and resource limitations in the Baltic Sea. In: Wulff F, Rahm L, Larsson P (eds) A systems analysis of the Baltic Sea. Ecological Studies 148. Springer, Berlin, p 177-210

> Hedman JE, Bradshaw C, Thorsson MH, Gilek M, Gunnarsson JS (2008) Fate of contaminants in Baltic Sea sediments: role of bioturbation and settling organic matter. Mar Ecol Prog Ser 356:25-38

HELCOM (Helsinki Commission) (2009) Eutrophication in the Baltic Sea: an integrated thematic assessment of the effects of nutrient enrichment and eutrophication in the Baltic Sea region. Balt Sea Environ Proc No. 115B

Ingalls AE, Aller RC, Lee C, Sun MY (2000) The influence of deposit-feeding on chlorophyll-a degradation in coastal marine sediments. J Mar Res 58:631-651

Jeffrey SW, Vesk M (1997) Introduction to marine phytoplankton and their pigment signatures. In: Jeffrey SW, Mantoura RFC, Wright SW (eds) Phytoplankton pigments in oceanography. UNESCO, Paris p 37-126

$>$ Josefson AB, Forbes TL, Rosenberg R (2002) Fate of phytodetritus in marine sediments: functional importance of macrofaunal community. Mar Ecol Prog Ser 230:71-85

Karlson K, Hulth S, Ringdahl K, Rosenberg R (2005) Experimental recolonisation of Baltic Sea reduced sediments: survival of benthic macrofauna and effects on nutrient cycling. Mar Ecol Prog Ser 294:35-49

Karlson AML, Nascimento FJA, Näslund J, Elmgren R (2010) Higher diversity of deposit-feeding macrofauna enhances phytodetritus processing. Ecology 91: 1414-1423

> Karlson AML, Näslund J, Ryden SB, Elmgren R (2011) Polychaete invader enhances resource utilization in a species poor system. Oecologia 166:1055-1065

Klais R, Tamminen T, Kremp A, Spilling K, Olli K (2011) Decadal-scale changes of dinoflagellates and diatoms in the anomalous Baltic Sea spring bloom. PLoS ONE 6: e21567

Kristensen E, Hansen T, Delefosse M, Banta GT, Quintana CO (2011) Contrasting effects of the polychaetes Marenzelleria viridis and Nereis diversicolor on benthic metabolism and solute transport in sandy coastal sediment. Mar Ecol Prog Ser 425:125-139

Leipe T, Tauber F, Vallius H, Virtasalo J and others (2011) Particulate organic carbon (POC) in surface sediments of the Baltic Sea. Geo-Mar Lett 31:175-188

Levin LA (2003) Oxygen minimum zone benthos: adaptation and community response to hypoxia. Oceanogr Mar Biol Annu Rev 41:1-45

> Levin LA, Blair NE, DeMaster DJ, Plaia G, Fornes W, Martin C, Thomas CJ (1997) Rapid subduction of organic matter by maldanid polychaetes on the North Carolina slope. J Mar Res 55:595-611

Mattila J, Kankaanpää H, Llus E (2006) Estimation of recent sediment accumulation rates in the Baltic Sea using artificial radionuclides $137 \mathrm{Cs} 239240 \mathrm{Pu}$ as time markers. Boreal Environ Res 11:95-107

- Maximov AA (2011) Large-scale invasion of Marenzelleria spp. (Polychaeta; Spionidae) in the Eastern Gulf of Finland, Baltic Sea. Russ J Biol Invasions 2:11-19

Morata N, Renaud PE (2008) Sedimentary pigments in the western Barents Sea: a reflection of pelagic-benthic coupling? Deep-Sea Res II 55:2381-2389

Norkko J, Reed DC, Timmermann K, Norkko A and others (2012) A welcome can of worms? Hypoxia mitigation by an invasive species. Global Change Biology 18:422-434

Quintana CO, Tang M, Kristensen E (2007) Simultaneous study of particle reworking, irrigation transport and reaction rates in sediment bioturbated by the polychates Heteromastus and Marenzelleria. J Exp Mar Biol Ecol 352:392-406

Quintana CO, Hansen T, Delefosse M, Banta G, Kristensen E (2011) Burrow ventilation and associated porewater irrigation by the polychaete Marenzelleria viridis. J Exp Mar Biol Ecol 397:179-187

Sandberg J (2007) Cross-ecosystem analyses of pelagic food web structure and processes in the Baltic Sea. Ecol Modell 201:243-261

Schiedek D (1997) Marenzelleria cf. viridis (Polychaeta: Spionidae) - ecophysiological adaptations to a life in the coastal waters of the Baltic Sea. Aquat Ecol 31:199-210

Solan M, Cardinale BJ, Downing AL, Engelhardt KAM, Ruesink JL, Srivastava DS (2004) Extinction and ecosystem function in the marine benthos. Science 306: 1177-1180

Sun MY, Dai J (2005) Relative influences of bioturbation and physical mixing on degradation of bloom-derived particulate organic matter: clue from microcosm experiments. Mar Chem 96:201-218

> Sun MY, Lee C, Aller RC (1993) Anoxic and oxic degrada- 
tion of ${ }^{14} \mathrm{C}$-labeled chloropigments and a ${ }^{14} \mathrm{C}$-labeled diatom in Long Island Sound sediments. Limnol Oceanogr 38:1438-1451

Viitasalo-Frösén S, Laine AO, Lehtiniemi M (2009) Habitat modification mediated by motile surface stirrers versus semi-motile burrowers: potential for a positive feedback mechanism in a eutrophied ecosystem. Mar Ecol Prog Ser 376:21-32

Villnäs A, Norkko A (2011) Benthic diversity gradients and shifting baselines: implications for assessing environmental status. Ecol Appl 21:2172-2186

Wasmund N, Siegel H (2008) Phytoplankton. In: Feistel R, Nausch G, Wasmund N (eds) State and evolution of the Baltic Sea 1952-2005, a detailed 50-year survey of meteorology and climate, physics, chemistry, biology, and marine environment. John Wiley \& Sons, Hoboken, NJ, p 441-481

Wasmund N, Andrushaitis A, Lysiak-Pastuszak E, MüllerKarulis B and others (2001) Trophic status of the southeastern Baltic Sea: a comparison of coastal and open areas. Estuar Coast Shelf Sci 53:849-864

> Widbom B, Frithsen JB (1995) Structuring factors in a marine soft bottom community during eutrophication - an experiment with radiolabelled phytodetritus. Oecologia 101: 156-168

Woulds C, Cowie GL (2009) Sedimentary pigments on the Pakistan margin: controlling factors and organic matter dynamics. Deep-Sea Res II 56:347-357

Woulds C, Cowie GL, Levin LA, Andersson JH and others (2007) Oxygen as a control on sea floor biological communities and their roles in sedimentary carbon cycling. Limnol Oceanogr 52:1698-1709

Woulds C, Andersson JH, Cowie GL, Middelburg JJ, Levin LA (2009) The short-term fate of organic carbon in marine sediments: comparing the Pakistan margin to other regions. Deep-Sea Res II 56:393-402

Zettler ML, Bochert R, Bick A (1994) Röhrenbau und Vertikalverteilung von Marenzelleria viridis (Polychaeta: Spionidae) in einem inneren Küstengewässer der südlichen Ostsee. Rostock Meeresbiol Beitr 2:215-225 
Appendix 1.

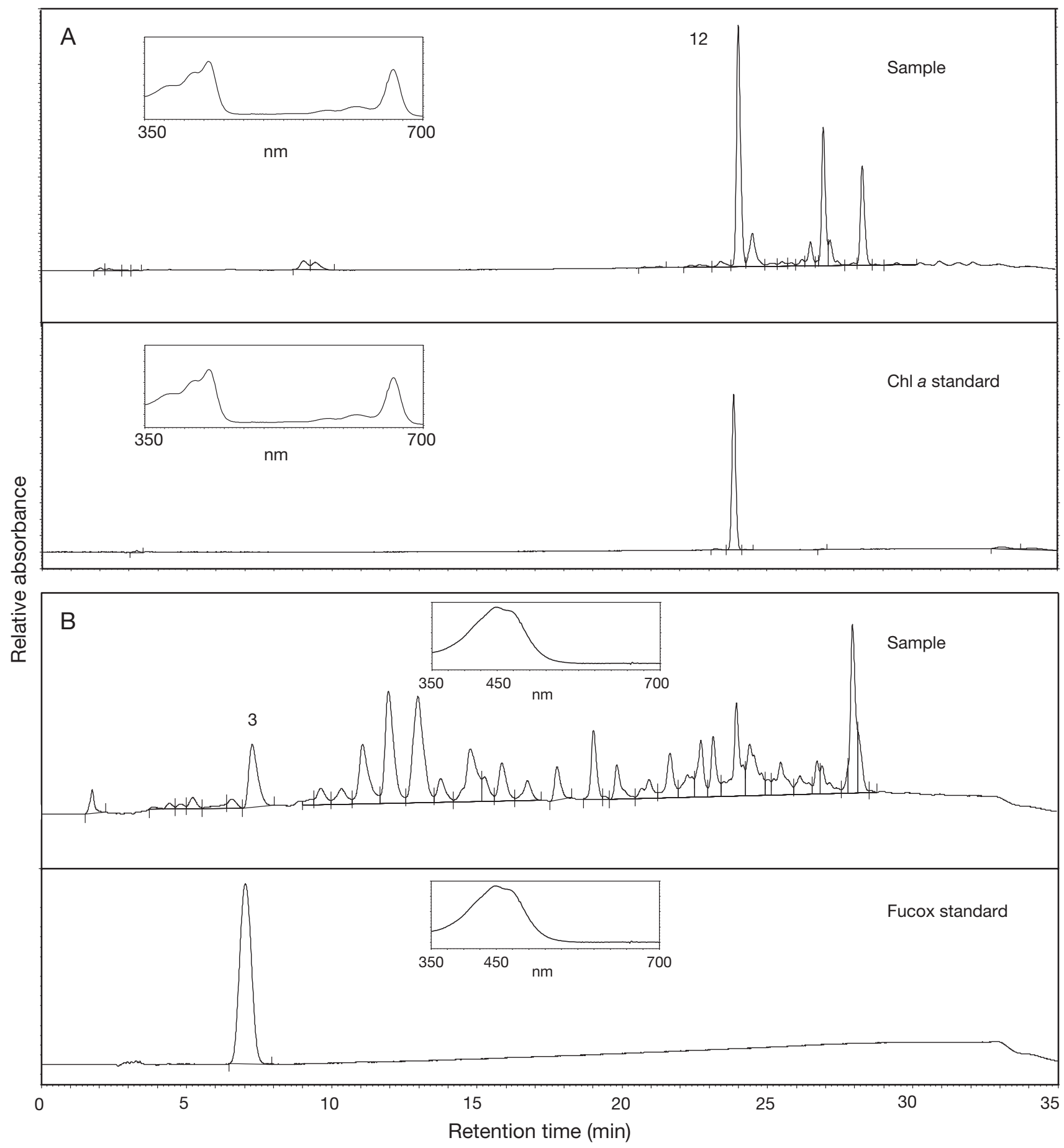

Fig. A1. Illustration of peak identification procedure of (A) chl a (peak no. 12) and (B) fucoxanthin (peak no. 3) showing absorbance chromatograms at $662 \mathrm{~nm}$ and $449 \mathrm{~nm}$ respectively from a sediment sample at $5-8 \mathrm{~cm}$ sediment depth in the Gulf of Finland (Stn GOF2) and of standards of the 2 pigments. Absorbance spectra for each sample and standard are shown as insets. Identical spectra of pigment peak in sediment sample and of standard peak suggest that peak in sediment sample is clean, i.e. represents only 1 pigment. Vertical lines delimit peaks of different pigments, and thin horizontal lines are peak baselines 